\title{
LAS RELACIONES ENTRE LA TUTELA PRECONTRACTUAL Y CONTRACTUAL DEL ACREEDOR: LA CONEXIÓN Y LA PROYECCIÓN-ABSORCIÓN
}

[The relationships between the pre-contractual and contractual protection of the creditor: the connection and the projection-absorption]

\section{Patricia Verónica López Díaz* Universidad de Valparaíso}

\section{RESUMEN}

El presente artículo tiene por propósito determinar, sistematizar y analizar las relaciones entre la tutela precontractual y contractual, a partir de la idea de conexión y proyecciónabsorción, ensayando una tipología de ellas que permitirá al acreedor advertir sus deslindes e inclinarse por una u otra, dependiendo del caso concreto en que se encuentre y del alcance de la tutela que pretenda obtener.

Palabras clave

Tutela del acreedor - Conexión de tutelas - Proyección-absorción.

\section{ABSTRACT}

The purpose of this article is to determine, systematize and analyze the relationships between precontractual and contractual protection, based on the idea of connection and projectionabsorption, testing a typology of them that will allow the creditor to notice their boundaries and lean towards one or the other, depending on the specific case in which it is found and the scope of the protection it intends to obtain.

KEY WORDS

Creditor's Protection - Connection of protections - Projection-absorption.

ReCibido el 12 de septiembre de 2017 y Aprobado el 12 de mayo de 2018

* Licenciada en Ciencias Jurídicas y Sociales, Universidad Adolfo Ibáñez. Doctora en Derecho, Pontificia Universidad Católica de Valparaíso. Profesora de Derecho civil, Universidad de Valparaíso. Dirección postal: Errázuriz 2120, Valparaíso. Correo electrónico: patriciaveronica.lopezdiaz@gmail.com. 


\section{INTRODUCCIÓN}

En la última década la doctrina nacional se ha abocado, preferentemente, al estudio de la tutela contractual ${ }^{1} \mathrm{y}$, en menor medida, al de la precontractual, fenómeno que es coincidente con el tardío interés que ella suscitó en la doctrina comparada ${ }^{2}$ y consecuencialmente en la nacio$\mathrm{nal}^{3}$ que la asoció exclusivamente a la indemnización de daños. Ha sido

${ }^{1}$ Entre otros, Vidal Olivares, Álvaro, Cumplimiento e Incumplimiento contractual en el Código Civil. Una perspectiva más realista, en Revista Chilena de Derecho 34 (2007) 1, pp. 41-59, VIDAl Olivares, Álvaro, La pretensión de cumplimiento específico y su inserción en el sistema de remedios por incumplimiento en el Código Civil, en Corral Talciani, Hernán-Rodríguez Pinto, María (editores), Estudios de Derecho Civil II (Santiago, LexisNexis, 2006), pp. 517-537, Pizarro Wilson, Carlos, Hacia un sistema de remedios al incumplimiento contractual, en GUZMÁn BRITO, Alejandro (editor), Estudios de Derecho Civil III (Santiago, LexisNexis, 2008), pp. 395-402, VIDAl Olivares, Álvaro, La carga de mitigar las pérdidas del acreedor y su incidencia en el sistema de remedios por incumplimiento, en GUZMÁN BRITO, Alejandro (editor), Estudios de Derecho Civil III (Santiago, LexisNexis, 2008), pp. 429-457, BRANTT ZuMARÁn, María Graciela, El caso fortuito y su incidencia en el derecho de la responsabilidad contractual (Santiago, AbeledoPerrot LegalPublishing, 2010), Mejías Alonzo, Claudia, El incumplimiento resolutorio en el Código Civil (Santiago, AbeledoPerrot LegalPublishing, 2011), Pizarro Wilson, Carlos, Contra el efecto retroactivo de la resolución por incumplimiento contractual, en Elorriaga DE BONIS, Fabián (coordinador), Estudios de Derecho Civil VII (Santiago, AbeledoPerrot LegalPublishing Thomson Reuters, 2012), pp. 449-460, PizArro Wilson, Carlos, Notas acerca de los limites a la pretensión de cumplimiento del contrato, en Revista de Derecho Universidad Católica del Norte 21 (2014) 1, pp. 203-219, Prado López, Pamela, La colaboración del acreedor en los contratos civiles, (Santiago, Thomson Reuters La Ley, 2015), Contardo GonzÁlez, Juan Ignacio, Indemnización y resolución por incumplimiento (Santiago, Thomson Reuters La Ley, 2015), López Díaz, Patricia Verónica, La autonomía de la indemnización de daños por incumplimiento de un contrato bilateral en el Código Civil Chileno (Santiago, Thomson Reuters LegalPublishing, 2015) y DE LA Maza Gazmuri, Ínigo, Incumplimiento del vendedor. Estudios y sentencias (Santiago, Ediciones Der, 2017).

${ }^{2}$ Las primeras reflexiones en torno a ella se sitúan en el año 1861: IHERING, Rudolf v., "Culpa in contrahendo oder Schadensersatz bei nichtigen oder nicht zur Perfektion gelangten Verträgen", Jherings Jahrbucher fur die Dogmatik des heutigen romischen und deutschen Privatrechts (1861) 4 y su regulación se remonta a 1940, como lo evidencian los artículos 197 y 198 del Código Civil griego de ese mismo año y 1337 del Codice de 1942, precursores en esta materia.

3 En efecto, el interés surge a propósito de la indemnización de daños por ruptura injustificada de las tratativas preliminares, cuyo primer exponente es ROSENDE Álvarez, Hugo, Algunas consideraciones sobre la responsabilidad precontractual (Valparaíso, Ediciones Universitarias de Valparaíso, 1979) y continuará con la indemnización complementaria a la nulidad, examinada profusamente por RoDRíGUEZ 
sólo recientemente que ha comenzado a explorarse más detenidamente, proponiéndose la articulación de los medios de tutela precontractual en torno a un común denominador, atribuyéndole tal carácter a la nulidad, a la indemnización derivada de anomalías o disconformidades en la fase de formación del contrato y a la adaptación del contrato ${ }^{4}$, analizando sus particularidades 5 .

Sin embargo, con antelación a tales disquisiciones dogmáticas, Iñigo de la Maza ya había asentado a propósito de la ausencia de las cualidades presupuestas de la cosa en el contrato de compraventa, una vinculación vertical y horizontal entre algunos de los medios de tutela contractuales y precontractuales contemplados en nuestro Código Civil ${ }^{6}$. Dicha sistematización no podía contemplar, por ejemplo, la adaptación del contrato, pues no se había intentado todavía su incardinación en la tutela precontractual a partir de una relectura de las normas contenidas en el Código $^{7}$ ni extenderse, por constituir una primera aproximación a un tópico inexplorado, a relaciones más alambicadas que podrían suscitarse entre la tutela precontractual y la tutela contractual.

En esta oportunidad, pretendemos, precisamente indagar y sistematizar

Grez, Pablo, Inexistencia y nulidad en el Código Civil. Teoría Bimembre de la Nulidad (Santiago, Editorial Jurídica de Chile, 1995), pp. 290-303 y BARAONA GonZÁlez, Jorge, La nulidad de los actos jurídicos: consideraciones históricas y dogmáticas (Bogotá, Pontificia Universidad Javeriana-Ibáñez, 2012), pp. 88-101. Un análisis más exhaustivo de este tópico en LÓPEz DíAz, Patricia Verónica, Los supuestos y el alcance de la indemnización de daños como medio de tutela precontractual en el Código Civil chileno y su eventual confluencia con la indemnización por incumplimiento, en Revista Ius et Praxis 24 (2018) 1, en prensa.

4 Morales Moreno, Antonio Manuel, ¿Es posible construir un sistema precontractual de remedios? Reflexiones sobre la Propuesta de Modernización del Derecho de Obligaciones y Contratos en el marco del Derecho europeo, en AlbiEZ Dohrmann, Klaus Jochen (Director), Palazón Garrido, María Luisa - Méndez Serrano, María del Mar (coordinadores), Derecho Privado Europeo y Modernización del Derecho Contractual en España (Barcelona, Atelier, 2011), p. 409 y López DíAz, Patricia Verónica, Por la articulación de un sistema de medios de tutela precontractual en el Código Civil chileno, en Corral Talciani, Hernán- Manterola González, Pablo, Estudios de Derecho Civil XII (Santiago, Thomson Reuters, 2017), pp. 465-483.

${ }^{5}$ LÓPEZ, Patricia, Los supuestos y el alcance..., cit. (n. 3), López DíAz, Patricia Verónica, La adaptación del contrato como medio de tutela precontractual en el Código Civil chileno, en Revista de Derecho de Valdivia 31 (2018) 1, en prensa.

${ }^{6}$ De la Maza Gazmuri, Íñigo, La tutela del comprador frente a la ausencia de calidades presupuestas en la cosa, en Revista de Derecho de la Pontificia Universidad Católica de Valparaíso 43 (2014), pp. 117-159.

7 Desafío que asumimos en López, Patricia, La adaptación del contrato..., cit. (n. 5). 
las relaciones entre ambas tutelas, examinando la existencia de una eventual conexión y proyección-absorción ${ }^{8}$, con el propósito de avanzar en la construcción de una tipología que ilustre al acreedor los contornos de cada cual para que escoja, de conformidad al interés que pretenda proteger y la tutela que persiga alcanzar, la estrategia de protección frente a las anomalías o disconformidades que puedan suscitarse en una u otra fase.

Para alcanzarlo dividiremos este artículo en dos secciones. La primera tratará la relación de con exión a partir de los contratos preparatorios, esto es, la contigüidad entre ambas, con especial atención en el contrato de promesa, ya que es el único tipificado en nuestro Código (II). Posteriormente, se examinará la relación de proyección, identificando los supuestos en que es posible advertirla y precisando cuándo opera una absorción entre ambas tutelas por voluntad del acreedor (III). Examinados tales tópicos, se formularán las conclusiones.

\section{PRIMERA RELACIÓN: LA CONEXIÓN ENTRE LA TUTELA PRECONTRACTUAL Y CONTRACTUAL ${ }^{9}$}

Cualquier jurista que emprenda la lectura del Código Civil chileno, fácilmente constatará que la regulación de los contratos preparatorios no concitó la especial atención de nuestro legislador. En efecto, únicamente se encuentra normado el contrato de promesa en el artículo 1554 en forma aparentemente restrictiva y excepcional ${ }^{10}$, pues si bien la promesa de celebrar un contrato obliga, ello ocurrirá en la medida que se cumplan los cuatro requisitos que el precepto indica. Tales son la escrituración de la promesa, que el contrato prometido no sea de aquellos que la ley declara ineficaces, que la promesa contenga un plazo o condición que fije la época de celebración del contrato y que en ella se especifique de tal manera el contrato prometido que sólo falten, para que sea perfecto, la tradición de la cosa o las solemnidades que las leyes prescriban. Con todo, esta regulación no es tan estricta como pareciera, dado que don Andrés

${ }^{8}$ Denominaciones aparentemente abstractas, pero cuya utilización justificaremos a lo largo de esta investigación.

9 El contenido de este apartado fue expuesto en la ponencia Los contratos preparatorios: entre la fase precontractual y contractual, presentada en la Cátedra por el Derecho Continental 2016 Los contratos en el nuevo derecho civil francés, el 9 de septiembre de 2016, inédita.

${ }^{10}$ Un exhaustivo análisis de este contrato en Abeliuk Manasevic, René, Contrato de promesa, de opción y otros acuerdos previos ( $3^{\text {a }}$ edición, Santiago, AbeledoPerrot LegalPublishing, 2012) y De la Maza Gazmuri, Ínigo, El contrato de promesa. La mirada de los tribunales (Santiago, Thomson Reuters, 2014). 
Bello le confirió un alcance general, a diferencia del Code de 1804 y el Código Civil español que en sus artículos 1589 y 1451, respectivamente, lo circunscribieron a la compraventa ${ }^{11}$. En efecto, lo ubicó en el Título XII del Libro IV a propósito del efecto de las obligaciones, decisión que si bien dogmáticamente se ha criticado ${ }^{12}$, permite otorgarle la amplitud que probablemente tendría si se hubiera situado en la teoría general de los contratos, de la que nuestro Código también prescinde.

Nada se dice, en cambio, del contrato de opción, si se adhiere a aquella corriente doctrinaria que lo concibe como contrato preparatorio ${ }^{13} \mathrm{ni}$ del pacto de preferencia, acuerdos de exclusividad, cartas de intenciones, cierre de negocios y otros acuerdos preliminares, y no existe a la fecha un proyecto de reforma orientado en ese sentido, como acontece en la Propuesta de Código Civil presentada por la Asociación de Profesores de Derecho Civil en España $(P A P C D)$ a los Libros Quinto y Sexto, que regula precariamente el contrato marco y más completamente la promesa de contrato en los artículos 522-2 y 522-3 ${ }^{14}$. Otro tanto ocurre en la Ordenanza $N^{\circ}$ 2016-131 de 10 de febrero de 2016 que modificó el Code en materia de Obligaciones y Contratos en general, pues disciplina el pacto de preferencia y la promesa unilateral en sus artículos 1123 y 1124 , respectivamente ${ }^{15}$. Sin embargo, desde la entrada en vigencia del Código Civil hasta nuestros días, la doctrina y la jurisprudencia, en virtud del principio de la autonomía de la voluntad, y específicamente, del sub principio de libertad contractual, ha admitido la celebración de acuerdos preparatorios de diversa índole, tales como las arras, cierre de negocios y leasing ${ }^{16}$, en la medida que no

${ }^{11}$ El artículo 1589 del Code señalaba: "La promesa de venta equivale a la compraventa cuando existe consentimiento reciproco de las dos partes sobre la cosa y el precio". Por su parte, el artículo 1451 del Código Civil español dispone lo siguiente: "La promesa de vender o comprar, habiendo conformidad en la cosa y en el precio, dará derecho a los contratantes para reclamar reciprocamente el cumplimiento del contrato. Siempre que no pueda cumplirse la promesa de compra y venta, regirá para vendedor y comprador, según los casos, lo dispuesto acerca de las obligaciones y contratos en el presente libro".

12 Por todos Abeliuk, René, cit. (n. 10), pp. 1-2.

13 Sobre la calificación del contrato de opción como preparatorio o definitivo véase ABELIUK, René, cit. (n. 10), pp. 198-201.

${ }_{14}$ Propuesta disponible en http://www.derechocivil.net/esp/pdf/PCC\%20-\%20 LIBROS\%20V\%20y\%20VI\%20(mayo\%202016).pdf

${ }^{15}$ Un análisis de estos preceptos en Deshayes, Olivier - Genicon, Thomas LAITHIER, Yves Marie, Reforme du droit des contracts, du régimen générale et de la prevue des obligations. Comentaire article par article (Paris, LexisNexis, 2016), pp. 138-163 y Chantepie, Gael-Latina, Mathias, La réforme du droit des obligations. Commentaire théorique et practique dans l'ordre du Code Civil (Paris, Dalloz, 2016), pp. 203-218.

${ }^{16}$ Para una completa revisión véase ABELIUK, René, cit. (n. 10), pp. 239-313. 
exista objeto o causa ilícita ni se advierta la ausencia de formalidades o consentimiento viciado. De otro lado, a partir de este principio, ha flexibilizado una interpretación inicialmente exegética y rígida del contrato de promesa, desenmarañando un conjunto de problemas derivados de ella.

Así, parecen haberse superado las discusiones en torno a la admisibilidad del contrato de promesa unilateral, la posibilidad de prometer celebrar un contrato consensual, combinar un plazo y una condición para fijar la época del mismo y anticipar el precio y la discusión relativa a aplicar la lesión enorme no a la fecha del contrato definitivo de compraventa sino a la del pago del precio ${ }^{17}$. En consecuencia, la ausencia de una regulación de contratos preparatorios distintos del contrato de promesa e incluso la restrictiva reglamentación de éste, no parece ser un problema, pues no han impedido ni desincentivado la celebración de ellos. El verdadero inconveniente, a nuestro juicio, se encuentra en la confusión que puede ocasionar el carácter híbrido del contrato preparatorio.

$Y$ es que si se analiza con atención esta categoría doctrinaria, es posible constatar que atraviesa dos fases del iter contractual. O, dicho de otra manera, se sitúa entre la fase precontractual y contractual, pues, de un lado, es propiamente un contrato principal e independiente, pero a la vez prepara el contrato definitivo. Esta constatación determina la necesidad de delimitar la promesa, por una parte, de otras conversaciones o negociaciones precontractuales que no tienen per se un carácter obligatorio, pero cuya ruptura injustificada puede acarrear consecuencias indemnizatorias -como las tratativas preliminares- y, de otra, precisar, aunque parezca evidente, en qué supuestos se incumple el contrato preparatorio. Las fronteras entre ambas etapas pueden tornarse difusas, aun cuando éstos estuvieran debidamente regulados en nuestro derecho, a diferencia de los contratos definitivos en que ellas están más claramente deslindadas.

La pregunta que surge entonces es la siguiente: ¿dónde se sitúa la frontera entre la fase precontractual y la contractual en los contratos preparatorios? La respuesta pareciera ser sencilla, en principio, pero un análisis más detenido revela que no lo es. Ella supone delimitar, por una parte, hasta dónde llega la negociación del contrato definitivo a través del contrato preparatorio, configurándolo, y por otra, a partir de cuándo la celebración del contrato definitivo resulta obligatoria, como consecuencia de haberse cumplido el preparatorio. Establecer tal separación acarreará como consecuencia la aplicación de un estatuto jurídico diverso que,

17 Véase AbeLiuK, René, cit. (n. 10), pp. 33-35, 37-45, 71-73 y 115 y DE LA MAZA, Ínigo, El contrato de promesa... cit. (n. 10), pp. 68-73 y 95-99. 
por lo mismo, facultará al contratante lesionado para instar por la tutela precontractual o contractual, respectivamente, en la medida que concurran los requisitos de alguno o algunos de los medios de tutela que integran ambos sistemas de protección.

Para alcanzar tal propósito distinguiremos ambas fases y nos valdremos de dos casos resueltos por la Corte Suprema con una doble finalidad: evidenciar que los confines entre una y otra etapa suelen confundirse no sólo entre los litigantes sino también en nuestros tribunales y constatar una conexión entre la fase precontractual y contractual, entendiendo por tal una relación tan solo de contigüidad que no permite efectuar una proyección de la tutela de una etapa a otra, radicándose en aquella en que la anomalía o disconformidad se generó. Nos abocaremos primeramente a la fase precontractual del contrato preparatorio y, seguidamente, a las vicisitudes de éste en la fase de ejecución o cumplimiento.

1. La fase precontractual del contrato preparatorio: la negociación del contrato definitivo y el perfeccionamiento del preparatorio (el doble efecto)

Una visión panorámica de lo que denominaremos "modelos de negociación de un contrato" nos permite advertir dos tipos: uno no vinculante y otro vinculante u obligatorio. El primero, como lo expresa su denominación, no conlleva la obligación de celebrar un contrato y se identifica con las tratativas preliminares que van modelando el acuerdo. El segundo, en tanto, se enmarca en la celebración de un contrato definitivo con la especificación del contenido y plazo de suscripción (como acontece en el contrato de promesa) o solo del contenido sin fijar la época del otorgamiento del contrato prometido (es el caso del cierre de negocios que sólo requiere la estipulación del pago de una multa ${ }^{18}$ ), que se identifica con el contrato preparatorio. Miradas las cosas desde esta perspectiva, podemos atribuirle al contrato preparatorio un carácter precontractual, toda vez que se sitúa en la fase de negociación previa a la celebración del contrato definitivo.

En este segundo modelo, la negociación que precede al contrato definitivo a través del preparatorio está constreñida, como ocurre en el contrato de promesa, a determinados requisitos que cumplen una doble función: por un lado, configuran el contenido del contrato definitivo y, por otro, determinan el contenido, nacimiento y la eficacia del contrato preparatorio, dado que constituyen elementos de su esencia. Por consiguiente,

\footnotetext{
18 Sobre este contrato véase PUELMA ACCORSI, Álvaro, Contratación comercial moderna: actos y contratos preparatorios, promesa, opción, cierre de negocio, comisión, corretaje, representación comercial, agencia, concesión mercantil, franchising, distribución, suministro, licencias, know how, apertura de créditos (Santiago, Editorial Jurídica de Chile, 2002), pp. 37-44 y AвELIUK, René, cit. (n. 10), pp. 274-279.
} 
y de conformidad al artículo 1444 del Código Civil, si no confluyen los elementos esenciales generales, el contrato de promesa no produce efecto alguno y si no concurren los elementos esenciales particulares, degenera en otro distinto, esto es, en cualquier acuerdo preparatorio consensual.

Pues bien, como se trata de elementos esenciales, las partes deben procurar su concurrencia para que el contrato se configure. Pero podría ocurrir que alguno de ellos, a pesar de encontrarse presente, igualmente acaree la ineficacia del contrato, porque no se ajustó a lo prescrito por el artículo 1554. Piénsese en la exigencia de especificar el contrato prometido contenida en el numeral cuatro de dicho artículo o en el supuesto en que habiéndose expresado, hechos sobrevinientes impidieran que su individualización cumpliera el propósito perseguido por el legislador. Así acontecería si, como lo exige el numeral 2 del artículo 1554, se incorporara una condición que fija la época de celebración de un contrato y ésta resulta fallida.

De allí que pueda sostenerse que los elementos esenciales del contrato de promesa tienen, según el caso, una carácter simple, pues sólo configuran el contrato prometido, o doble, dado que lo configuran y, a la vez, imponen a las partes la obligación que dicho elemento cumpla los requisitos previstos por ley, removiendo los obstáculos que pudieran surgir. Al primer grupo sólo pertenece la escrituración del contrato de promesa, porque éste consta o no consta por escrito. Si no se escritura, falta un requisito del contrato y, de conformidad al inciso final del artículo 1554 "no produce obligación alguna", deviniendo el contrato en nulo absoluto o inexistente, dependiendo de la doctrina a la que adhiramos. Con todo, cualquiera sea nuestra elección, quedaremos at rapados en la fase precontractual, activándose dicha tutela, tanto así que si nos plegamos a la tesis mayoritaria, procede la nulidad ${ }^{19}$, sin perjuicio que como lo ha admitido la jurisprudencia si concurren los requisitos de otro contrato preparatorio, como el cierre de negocios, degenere en éste y subsista como tal ${ }^{20}$.

19 Un análisis de esta discusión en la dogmática y en la jurisprudencia nacional en De la Maza, Íñigo, El contrato de promesa..., cit. (n. 10), pp. 31-33. Atendida la reciente tendencia doctrinaria que ha proporcionado argumentos históricos y de texto para sostener que la nulidad absoluta opera de pleno derecho, debería imponerse dicha tesis mayoritaria. Sobre tales postulados véase BARAONA, Jorge, cit. (n. 3), pp. 55-62 y 65 y SAN MARTín NeIRA, Lilian, La teoría de la inexistencia y su falta de cabida en el Código Civil Chileno, en Revista Chilena de Derecho 42 (2015) 3, pp. 760-762, 769-770 y 777-778.

20 Para una revisión jurisprudencial véase DE LA MAZA, Ínigo, El contrato de promesa... cit. (n. 10), pp. 33-37. 
Lo cierto es que en el supuesto que venimos comentando resulta lógico preguntarse el motivo por el cual el contrato no se escrituró. La interrogante que surge específicamente es si podría estimarse que tal omisión no incide en el perfeccionamiento del contrato, sino en la fase anterior de negociación, entendiendo así que se verificaría la infracción de un deber precontractual. A nuestro juicio, esta delimitación pasa por determinar si tal omisión es imputable al descuido o negligencia de ambas partes o al dolo o negligencia de una de ellas. Si es imputable a ambos, es lógico y equitativo que el contrato prometido no produzca efecto alguno. Pero, si es imputable a uno de ellos, la solución debería ser distinta, porque sería injusto hacer soportar los riesgos de tal actuación al otro contratante que confía en que su co-contratante realizará todas las gestiones tendientes a que concurran los requisitos necesarios para el perfeccionamiento del contrato de promesa.

Así ocurriría si uno de ellos impide la escrituración de la promesa, deliberadamente oculta que el contrato prometido recae sobre una cosa embargada por decreto judicial o un bien litigioso, o bien, se estipula una condición que se tiene por nula. Piénsese en la condición meramente potestativa que depende de la sola voluntad del deudor prevista en el inciso primero del artículo 1478 del Código Civil como ocurriría, por ejemplo, si se conviene que el contrato prometido no se celebrará si el deudor ejerce la facultad de desistirse. O se pacta una condición que se tiene por no escrita, como acontece tratándose de la condición resolutoria ininteligible o inductiva a un hecho inmoral o ilegal, según lo previene el inciso final del artículo 1480.

En todos estos supuestos se advierte, en definitiva, que el co-contratante incumplió su deber de colaboración en sede precontractual ${ }^{21}$, vulnerándose el deber de lealtad ${ }^{22}$, y más discutiblemente el deber de información (porque podría existir la carga de a u t o i n f o r m a r s e ${ }^{23}$ ), causándole daños cuya procedencia puede reconducirse a la indemnización extracontractual regulada en el Título 35 del Libro IV de nuestro Código Civil. Y es que, como acertadamente lo ha sostenido el profesor Enrique Barros, en el período precontractual "por un lado, no hay promesa, de

${ }^{21}$ Cuyo soporte dogmático se encuentra en el principio de buena fe que se proyecta durante todo el iter contractual. Un análisis de este deber en Prado, Pamela, cit. (n. 1).

${ }^{22}$ Para la construcción dogmática de este deber véase López, Patricia, Por la articulación de un sistema de medios..., cit. (n. 4), p. 471 y LOPEZ, Patricia, Los supuestos y el alcance..., cit. (n. 3).,

${ }^{23}$ Un estudio sobre este tópico en DE LA MAZA, Íñigo, Los límites del deber precontractual de información (Madrid, Civitas-Thomson Reuters, 2010). 
modo que tampoco puede haber contrato; por otro existe un grado variable de confianza que debe ser honrada por quien la ha creado" 24 .

Finalmente, también podría ocurrir que tratándose del contrato de promesa sea procedente la adaptación del contrato en determinados supuestos de error vicio unilateral o compartido ${ }^{25}$, en la medida que ésta sea conveniente y posible. Inclinarse por tal alternativa, a partir de la idea que tal adaptación propende a la satisfacción directa del interés del errans y de la aplicación de los principios de buena fe y renunciabilidad de los derechos, consagrados, respectivamente, en los artículos 1546 y 12 de nuestro Código Civil, sobre los que dicho medio de tutela se sustenta ${ }^{26}$, permitiría salvar el contrato preparatorio para suscribir el definitivo. Y es que incluso en un contrato tan regulado como el de promesa en que se exige que el contrato prometido quede especificado de tal manera que sólo falte, para que quede perfecto, la tradición de la cosa o las solemnidades que las leyes prescriben, es posible que una o ambas partes incurran en una falsa representación de la realidad. La exigencia de especificación no sólo implica que estén presentes los elementos de la esencia del contrato prometido (lo que desde luego descarta el error obstáculo), sino también la especificación de la prestación prometida y de la contraprestación, lo que da cabida al error sustancial. Así acontecerá, por ejemplo, si el contrato prometido es un contrato de confección de obra material y los baldosines con que se efectuará la construcción son de un material distinto al convenido o tienen propiedades antitérmicas. En tal supuesto si, estando facultado uno de los contratantes para impugnar el contrato por error, el otro manifiesta su disposición a cumplir o cumpliera el contrato, tal cual había sido entendido por aquel (error unilateral) o incurriendo ambos en él (error compartido), el juez le otorgara el sentido que razonablemente le hubieran conferido las partes de no existir error, procederá la adaptación del contrato y, por consiguiente, éste subsistirá.

\section{La fase contractual del contrato preparatorio: el incumplimiento de} las obligaciones derivadas de los elementos de la esencia y de la obligación de celebrar el contrato definitivo

Sabido es que una vez que concurren los requisitos del contrato pre-

24 Barros Bourie, Enrique, Tratado de responsabilidad civil extracontractual (Santiago, Editorial Jurídica de Chile, 2006), p. 1004.

${ }^{25}$ Morales, Antonio Manuel, ¿Es posible construir un sistema precontractual..., cit. (n. 4), pp. 412-414.

${ }^{26}$ Morales Moreno, Antonio Manuel, El error en los contratos (Madrid, Ceura, 1988), pp. 87-88, premisas que hemos adaptado para derecho chileno en LópEZ DíAz, Patricia Verónica, La adaptación del contrato..., cit. (n. 5). 
paratorio éste se perfecciona y surge la obligación de suscribir el contrato definitivo que no se podía o no se quería suscribir a la época de celebración del preparatorio. Resulta claro, entonces, que nos situamos en la fase contractual y que el incumplimiento de dicha obligación activa el sistema de medios de tutela por incumplimiento ${ }^{27}$. Por consiguiente, el contratante podrá demandar el cumplimiento específico, la indemnización de perjuicios, la resolución del contrato, la cláusula penal estipulada para el incumplimiento y la excepción de contrato no cumplido.

Así acontecerá si uno de los promitentes no concurre a suscribir la escritura pública del contrato de compraventa de un inmueble. Sin embargo, como ya lo adelantamos, los elementos esenciales del contrato de promesa pueden llevar envuelta la obligación de remover los obstáculos que impidan la satisfacción de sus requisitos exigidos por ley. Tal es el caso de la condición en las hipótesis previstas en el artículo 1481 del Código Civil que, en su inciso primero, regula un supuesto en que ella debe tenerse por fallida y, en el segundo, otro en que debe tener por cumplida fictamente. Así, cuando la condición deja de cumplirse porque la otra persona de cuya voluntad depende no puede o no quiere cumplirla, se tendrá por fallida, incumpliéndose dicha obligación, lo que activará los medios de tutela contractuales. En cambio, como lo indica el profesor Daniel Peñailillo, si el obligado a cumplirla se vale de medios ilícitos para que ésta no se verifique o para que la otra persona de cuya voluntad depende en parte su cumplimiento no coopere a él, se tendrá por cumplida, fictamente la condición, en la medida que haya existido dolo ${ }^{28}$, quedando el contrato preparatorio perfecto. Distinto es el caso si ha existido culpa del deudor, pues no habría cumplimiento tácito, sino que nuevamente la condición debe tenerse como fallida ${ }^{29}$.

Piénsese, por ejemplo, en el caso que se establezca como condición que el promitente comprador obtenga la aprobación de la subdivisión de un predio, la regularización de éste o la aprobación de un proyecto de construcción que permita el libre acceso vehicular sin requerir la ejecución

${ }^{27}$ Una visión panorámica de este sistema en PiZArro WiLson, Carlos, Hacia un sistema de remedios..., cit., (n. 1), pp. 395-402 y López Díaz, Patricia Verónica, La tutela precontractual y contractual del acreedor en el Código Civil chileno: dos sistemas estructuralmente diversos, pero iplenamente coherentes y convergentes?, en Revista Chilena de Derecho Privado 29 (2017), pp. 9-98.

${ }^{28}$ Peñallillo Arévalo, Daniel, El cumplimiento ficto de la condición, en Revista de Derecho de la Universidad de Concepción 178 (1985), pp. 19-21.

${ }^{29}$ Ibid., pp. 20 y 21 . El autor explica que la regla prevista en el inciso segundo del artículo 1481 se torna inaplicable en caso de culpa, porque lo que se persigue con ella es frustrar la pretensión maliciosa del deudor que actúa con el propósito o finalidad de impedir el cumplimiento de la condición. 
de obras mayores ni la intervención del Ministerio de Transportes y ello no ocurra. En tal caso la condición se tendrá por cumplida fictamente o por fallida, si la omisión fue dolosa o culposa, respectivamente. Este último supuesto fue precisamente el que se debatió en Inmobiliaria Los Canelos S.A. con Inmobiliaria e Inversiones Sevilla Ltda., pues el promitente vendedor alegó incumplimiento del contrato de promesa de compraventa y demandó su ejecución y, en subsidio, la resolución del mismo con indemnización, rechazándose su pretensión en primera y segunda instancia, confirmándose esa decisión por la Corte Suprema. En efecto, en sentencia de 24 de marzo de 2014, desestimó el recurso de casación en el fondo interpuesto por el demandante en el que denuncia que eximir de responsabilidad al promitente comprador por no obtener la referida aprobación municipal infringe las reglas de la conmutatividad y los principios de fuerza obligatoria y buena fe en los contratos, contenidas en los artículos 1441, 1545 y 1546 del Código Civil, precisando dicho tribunal "que la condición prevista por los contratantes para el otorgamiento del contrato de compraventa prometido resultó fallida por causa no imputable al deudor ${ }^{330}$.

Y es que, como se consignó en autos, aun cuando el promitente comprador no subsanó los defectos formales que se formularon a la solicitud de aprobación municipal exigida, el acceso vehicular requerido implicaba la intervención y ejecución de obras mayores, de modo que al no cumplirse la condición se activó la cláusula sexta del contrato que prescribía que, en tal evento, "el contrato no produce efecto alguno". En consecuencia, no existió incumplimiento. Con todo, podría pensarse que el resultado habría sido distinto si el promitente vendedor hubiera acreditado que el promitente comprador desplegó una conducta que infringía los deberes que la buena fe impone a quienes negocian un contrato o que, al margen que la condición estuviera fallida, en virtud de la función integradora de la buena fe contractual a que alude el artículo 1546 del Código Civil, debía entenderse dicha condición como una obligación diversa a aquella propia del contrato de promesa ${ }^{31}$, hipótesis en la cual ya no se trataría de

${ }^{30}$ Considerando décimo, Inmobiliaria Los Canelos S.A. con Inmobiliaria e Inversiones Sevilla Ltda.: Corte Suprema, 24 de marzo de 2014 (casación en la forma y casación en el fondo), en www.vlex.com, $\mathrm{N}^{\circ}$ VLEX 500403234, comentada en DE la Maza Gazmuri, Íñigo, Condiciones y obligaciones en el contrato de promesa. Corte Suprema, rol 512-2013, 24 de marzo de 2014. Cita en línea: CL/JUR/497/2014, Contratos Especiales, en Revista Chilena de Derecho Privado 22 (2014), pp. 271-284. El destacado es nuestro.

${ }^{31}$ Para una tipología de otras obligaciones posibles en el contrato de promesa Abeliuk, René, cit. (n. 10), pp. 141-153. 
un problema precontractual que determina la ineficacia del contrato, sino de un supuesto de incumplimiento. Sin embargo, en ambos supuestos, la pretensión indemnizatoria no hubiera prosperado, pues debe existir una relación de causalidad entre el daño y la no celebración del contrato prometido, lo que no acontece en este caso, pues, como se ha referido más arriba, la voluntad de las partes era celebrarlo sólo si no era necesario ejecutar obras mayores ${ }^{32}$.

En otras ocasiones no se ha advertido con claridad que la etapa contractual no se configura, sino que el problema se sitúa en un estadio anterior, arrastrando artificialmente supuestos que deben permanecer en la fase precontractual del contrato definitivo o, si se quiere, en la configuración del contrato preparatorio, a la fase de incumplimiento del contrato preparatorio, lo que no sólo se traduce en una errónea calificación jurídica del problema, sino que además conlleva la aplicación de un estatuto jurídico improcedente. Pensemos en el siguiente caso conocido por la Corte Suprema en Lange Haensgen con Ibáñez Santa María el 23 de septiembre de $2015^{33}$. Un sujeto formula a otro una oferta de compra de un departamento que se individualiza a un determinado precio, sujeta a la condición de efectuarse en éste trabajos de modificación y reacondicionamiento, la que es aceptada sin reparos por el destinatario. Todo ello tiene lugar a través de correos electrónicos, precisándose que se formalizaría a través de un contrato de promesa de venta, lo que en definitiva no ocurrió, pues el oferente no remitió los antecedentes para proceder a su elaboración. El destinatario de la oferta adujo que se configuró un contrato preparatorio mediante la aceptación de la oferta realizada distinto a la promesa y al haberse negado el oferente a suscribirlo incurrió en incumplimiento, facultándolo para solicitar la resolución más la indemnización de daños. El oferente, en cambio, sostuvo que nunca existió contrato sino negociaciones, de modo que al no haberse configurado el vínculo contractual no podía prosperar la resolución. En primera instancia se declaró resuelto el contrato preparatorio y sólo se concedió la indemnización del daño emergente. Sin embargo, tal pronunciamiento fue revocado en segunda instancia, declarándose que entre las partes no existió contrato de promesa ni otro preparatorio que haya originado la obligación de celebrar un contrato futuro.

Nuevamente nos encontramos ante un problema de calificación

32 De la Maza, Íñigo, Condiciones y obligaciones en el contrato... cit. (n. 30), p. 278. Sobre las tres perspectivas para abordar el supuesto de hecho de este caso Ibid., pp. 274-278.

${ }^{33}$ Lange Haensgen con Ibáñez Santa María: Corte Suprema, 23 de septiembre de 2015 (casación en el fondo), en www.vlex.com, NVLX 583125862. 
jurídica que exige determinar si estamos en la fase precontractual del contrato preparatorio o, por el contrario, éste ya se configuró, desplazándose el problema a la fase contractual, específicamente, a su inejecución. Para resolver esta interrogante, como acertadamente sostuvo la Corte Suprema, conociendo del recurso de casación en el fondo interpuesto por el demandante, debe calificarse jurídicamente el intercambio de correos electrónicos y precisar si éstos configuran: $i$ ) primero, un contrato de promesa; ii) segundo, un contrato preparatorio distinto a la promesa que obliga a celebrar un contrato de compraventa; iii) tercero, una promesa de celebrar una promesa de contrato; iv) cuarto, tratativas preliminares que no generan vínculo contractual alguno o; $v$ ) quinto, el consen timien to de celebrar un contrato. Como es evidente no existe un contrato de promesa, porque faltan los requisito exigidos en los numerales 3 y 4 del artículo 1554 del Código Civil, toda vez que no se establece un plazo o condición que fije la época de celebración del contrato ni se especifica de tal manera el contrato prometido que sólo falte para que sea perfecto la tradición de la cosa o las solemnidades que las leyes prescriben ${ }^{34}$. De otro lado, tampoco se trata de una promesa de celebrar una promesa de contrato, porque como indica Abeliuk ${ }^{35}$, esa promesa debería cumplir los requisitos del referido artículo 1554, lo que en definitiva implica que no podría haber una promesa de otorgar otra promesa.

Lo que en realidad ocurrió, como precisó dicho tribunal, fue que se formó el consentimiento para celebrar un contrato de compraventa de inmueble "en el marco de un acuerdo de negociación en progreso", ya que hubo oferta y aceptación en tal sentido, pero éste no llegó a celebrarse, porque la compraventa de un inmueble y la promesa de contrato, como se desprende del inciso segundo del artículo 1801 y $1554 \mathrm{~N}^{\circ} 1$, son contratos solemnes. En otras palabras, el acuerdo no fue suficiente, de modo que no puede existir incumplimiento. Siguiendo este razonamiento, la Corte rechazó el recurso de casación en el fondo interpuesto por el oferente comprador por infracción de los artículos 1437 a 1439 y 1445 del Código Civil y los artículos 98, 100, 101 y 106 del Código de Comercio, en el que denuncia que los jueces de instancia desconocieron la existencia de un contrato preparatorio y su fuerza obligatoria, afirmando que éste fue incumplido por el oferente, lo que habilita para requerir la resolución más la indemnización de daños ${ }^{36}$. 33).

${ }^{34}$ Considerando séptimo de Lange Haensgen con Ibáñez Santa María, cit. (n.

35 Abeliuk, René, cit. (n. 10), p. 270.

${ }^{36}$ Considerandos octavo y noveno de Lange Haensgen con Ibánez Santa María, 
De lo dicho hasta acá fluye con claridad que el actual problema de los contratos preparatorios en nuestro ordenamiento jurídico no es necesariamente su falta de regulación, sino desconocer que entre la tutela precontractual y contractual existe una relación de conexión que revela que, dichos contratos, constituyen un híbrido que se sitúa en ambas fases y que, por lo mismo, debemos calificar jurídicamente la etapa en que el problema se presenta para determinar correctamente el estatuto jurídico aplicable. Así evitaremos desplazar la ausencia de un requisito de configuración a la fase de incumplimiento (como adujo el demandante en Inmobiliaria Los Canelos S.A. con Inmobiliaria e Inversiones Sevilla Ltda.) o calificar como contrato de promesa el consentimiento para celebrar un contrato de promesa de venta de un inmueble que, en definitiva, no se celebró y alegar su incumplimiento (como lo sostuvo el actor en Lange Haensgen con Ibáñez Santa María).

\section{SEGUNDA RELACIÓN: LA PROYECCIÓN-ABSORCIÓN ENTRE LA TUTELA PRECONTRACTUAL Y CONTRACTUAL}

Una revisión de las anomalías suscitadas en la fase precontractual revela que existen supuestos en que éstas pueden proyectarse a la contractual, quedando, en tales casos, la tutela precontractual absorbida por la contractual $^{37}$, porque el acreedor ha decidido inclinarse por ésta última en ejercicio de su derecho de opción. Como se advierte, nos estamos refiriendo al supuesto en que escoja una de ellas y no que demande un medio de tutela contractual en subsidio de otro precontractual o viceversa,

cit. (n. 33).

${ }^{37}$ La expresión proyección si bien podría parecer un tanto abstracta ha sido acunada progresivamente por a civilística nacional y comparada para graficar precisamente el desplazamiento de un medio de tutela desde la fase precontractual a la contractual, motivo por el cual decidimos emplearla en esta investigación (véase Morales Moreno, Antonio Manuel, Incumplimiento de contrato y lucro cesante (Navarra, Thomson Civitas, 2010), pp. 90-91, García Rubio, María Paz-Otero Crespo, Marta, La responsabilidad precontractual en el derecho contractual europeo, en InDRET Revista para el análisis del Derecho 2 (2010), disponible en http://www.indret.com/ pdf/731 es.pdf., p. 56, LópEz, Patricia, La indemnización de daños por vicios... cit. (n. 47), pp. 680 y 681y Prado López, Pamela, El dolo causal: su repercusión en el contrato, en Revista Ius et Praxis 22 (2016) 2, pp. 426 y 442-451.

En lo que concierne a la expresión absorción, ella también ha sido utilizada para ilustrar el fenómeno jurídico según el cual la tutela del acreedor queda radicada en una determinada fase (véase DE LA MAZA, Íñigo, Los límites del deber precontractual... cit. (n. 23), p. 274), consecuencia lógica del desplazamiento desde una fase a otra, pues sólo una tutela es la que debe prevalecer. 
pues en ese caso no renuncia a alguno de ellos, sino que establece procesalmente una ordenación jerárquica entre éstos.

En otro sitio hemos abogado por reconocer al contratante perjudicado por las anomalías o disconformidades acaecidas en la fase precontractual el derecho de opción entre estos medios de tutela y aquellos propios del incumplimiento, invocando como argumentos el carácter sucedán eo de éste respecto del derecho de crédito, las dificultades probatorias a las que pueda verse enfrentado el acreedor en ambos sistemas de tutelas, la amplitud de mecanismos de protección, efectividad y flexibilidad tuitiva que éstos presentan ${ }^{38}$, la asimetría del alcance de tales tutelas y la existencia de determinados artículos del Código Civil, tales como el 1814 y 1932, que así permitirían sostenerlo ${ }^{39}$. De modo que nos remitimos a ellos y damos por sentado que el acreedor puede optar por una tutela u otra. Pero de ello no se sigue que todas las anomalías precontractuales se subsuman en supuestos de incumplimiento, toda vez que, como veremos, algunas de ellas no encuentran correlato en la fase contractual, justificándose, por consiguiente, la existencia de la fase precontractual.

1. Las anomalías o disconformidades que pueden proyectarse desde la fase precontractual a la contractual

Un detenido examen de la tutela precontractual y contractual arroja como resultado que existen, al menos, cinco anomalías o disconformidades suscitadas en la fase de formación del contrato que pueden desplazarse a la de su ejecución. Tales son la infracción de las obligaciones de advertencia, la existencia de vicios redhibitorios, la falta de objeto, el error y el dolo en la medida que ambos vicien el consentimiento, subsumiéndose los dos primeros supuestos en la indemnización por incumplimiento, el cuarto y el quinto en la resolución contractual si ellos han determinado la frustración del interés del acreedor y el tercero en la indemnización de daños o en la resolución, dependiendo del interés que pretenda tutelar el acreedor. Las trataremos en este mismo orden, examinando con mayor exhaustividad aquellos supuestos que han sido escasamente explorados por nuestra dogmática.

a) La infracción de las obligaciones de advertencia. - La primera anomalía que puede proyectarse desde la fase precontractual a la contractual es la

38 LÓPEZ, Patricia, La tutela precontractual y contractual del acreedor... cit. (n. 27), pp. 69-77.

39 López Díaz, Patricia Verónica, Tutela precontractual versus tutela contractual en el Código Civil chileno: ¿efecto espejo o reflejo", en Estudios de Derecho Civil XIII, en prensa. 
vulneración de las obligaciones de advertencia. Como lo hemos apuntado en otro sitio $^{40}$, se trata de una figura incipientemente explorada en nuestra dogmática ${ }^{41}$, a diferencia de lo que ocurre en la comparada ${ }^{42}$, que puede presentarse tanto en la fase precontractual como contractual, perfilándose actualmente como una especial manifestación de la buena fe en los contratos de servicios, a partir de lo preceptuado en los artículos IV.C: 2:102 y IV.C. 2:108 del Draft Common Frame of Reference (DCFR).

La obligación de advertencia constituye una especie de obligación de información, toda vez que, como acertadamente precisa la profesora María Teresa Alonso Pérez ${ }^{43}$, no son asimilables a ellas, atendida su función, contenido, presupuesto y consecuencias derivadas de su infracción. En efecto, no tienen por propósito equilibrar las posiciones de las partes ni solventar ninguna asimetría informativa que pueda generar un vicio del consentimiento en la parte con déficit de información. La información que debe suministrarse no es idéntica, porque los datos que deben informarse no son los mismos que deben advertirse, como se referirá más abajo al abordar el contenido de estas obligaciones. De otro lado, son exigibles en la medida que ambos sujetos o uno de ellos, según el caso, conozcan o tengan razón para conocer la información acerca de la cual deben advertir, exonerándose de ella cuando el prestatario o cliente ya conociera los riesgos objeto de dicha advertencia o tuviera razón para conocerlos, presumiéndose el conocimiento si tales hechos inusuales son obvios, atendiendo a los hechos y circunstancias conocidas por el cliente ${ }^{44}$. Finalmente, no acarrean la ineficacia del contrato como consecuencia de la configuración de un

${ }^{40}$ López Díaz, Patricia, Indemnización de daños autónoma por incumplimiento contractual. Vencimiento del término esencial. Infracción de obligaciones de advertencia. Daño moral y esfera de protección del contrato. Corte Suprema, 14 de noviembre de 2016, rol 5746-2016. Cita en Línea LEGALPUBLISHING CL/JUR/7557/2016, en Revista Chilena de Derecho Privado 28 (2017), p. 315.

${ }^{41}$ López, Patricia, Indemnización de daños autónoma ..., cit. (n. 40), pp. 315-316 y López, Patricia, Los supuestos y el alcance... cit. (n. 3).

${ }^{42}$ Fabre-Magnan, Muriel, De l'obligation d'information dans les contrats. Essai d'une théorie (Paris, L.G.D.J., 1992), pp. 379-383, Crespo Mora, María Carmen, Notas sobre la regulación del contrato de servicios en el derecho español y en el DCFR, en Bosh Capdeville, Esteve (director), Nuevas Perspectivas del Derecho contractual (Barcelona, Bosh, 2012), pp. 584-585 y Alonso PéREz, María Teresa, La función de las obligaciones precontractuales de advertencia en la formación del contrato de servicios (Estudio de Derecho Contractual Europeo), Indret Revista para el Análisis del Derecho 3 (2012), disponible en http://www.indret.com/pdf/914_es.pdf.

43 Alonso, María, cit. (n. 42), pp. 15 y 16.

${ }_{44}$ Así lo previenen los artículos IV.C: 2:102 (2), (6), (7) y IV.C: 2:108 (2), 6), (7) del DCFR. 
vicio del consentimiento, específicamente error y dolo, sino que tienden a la mantención del contrato.

Con todo, estas obligaciones persiguen un propósito distinto según la etapa del iter contractual en que concurran. En la fase de formación éstas asisten al prestador del servicio y al cliente y persiguen posibilitar que los sujetos que negocian concreten en el más alto grado el servicio a prestar y el precio, encauzando la relación precontractual. Dicho de otra forma, permiten que las partes pacten un determinado reparto de riesgos. En cambio, durante la ejecución del contrato sólo tienen cabida respecto del prestador del servicio y tienen por propósito trasladar al acreedor (prestatario) los riesgos de su no obtención definitiva o en las condiciones pactadas ${ }^{45}$.

Así, el artículo IV.C: 2:102 (1) del DCFR prescribe en términos generales que el contenido de estas obligaciones en la fase precontractual es el siguiente: el prestador debe advertir si, $i$ ) primero, no puede alcanzar el resultado indicado o previsto por el cliente; $i$ ) segundo, pueden resultar dañados otros intereses del mismo; iii) tercero, el servicio puede resultar económicamente más gravoso y; iv) cuarto, su consecución puede llevar más tiempo que el que razonablemente se ha estipulado; en cambio, el cliente o prestatario, debe advertir al prestador del servicio de cualquier hecho inusual que pueda determinar que el servicio resulte más gravoso o que retarde su ejecución. En tanto, de conformidad al IV.C: 2:108 (1) en la etapa de ejecución del contrato el contenido de la obligación se mantiene intacto para el prestador del servicio, más no para el prestatario a quien no se le impone ninguna obligación. De allí que se señale que se trata de obligaciones recíprocas sólo en sede precontractual ${ }^{46}$.

Pues bien, efectuada esta aclaración, la operación de proyecciónabsorción desde una fase a otra tendría lugar sólo respecto del prestador de servicios. Y es que, podría ocurrir que existiendo una obligación de advertencia que no se haya ejecutado en la fase precontractual, cuya inobservancia persista en aquella de cumplimiento del contrato, el acreedor decida instar por demandarla en esta última sede, lo que le permitirá reclamar el interés positivo y no el negativo o en la confianza. Así acontecería si el prestador del servicio - para quien existe la obligación de advertencia en ambas fases- no advierte al cliente al momento de la negociación del contrato que la construcción tardará unos meses más. O, tratándose del contrato de diseño, que carece de la competencia propia de un especialista en este rubro o que el diseño de los planos alcanzarán un valor superior

45 Fabre-Magnan, Muriel, cit. (n. 42), pp. 379-383, Crespo, María, cit. (n. 42), pp. 584-585 y Alonso, María, cit. (n. 42), pp. 10-13, 28 y 31.

46 Refiriéndose al contenido de estas obligaciones y calificándolas como recíprocas en sede precontractual, vid. Alonso, María, cit. (n. 42), pp. 6 y 19. 
al pactado y tal omisión subsiste una vez que éste comienza a ejecutarse, retardándose la construcción o deviniendo el contrato en más oneroso.

b) La existencia de vicios redhibitorios.- Como es bien sabido, nuestro legislador otorga al acreedor la facultad de demandar la indemnización de daños por la existencia de vicios redhibitorios en los artículos 1861, 1932, 1933, 2192 y 2203 del Código Civil en los contratos de compraventa, arrendamiento, mutuo y comodato, respectivamente, cuyo fundamento, indiscutidamente, se encuentra en la vulneración del deber precontractual de información ${ }^{47}$. Piénsese, por ejemplo, en ductos de ventilación o baldosines que presentan desperfectos que no permiten habitar un inmueble, defectos en máquinas o automóviles que impiden destinarlos al uso para el que han sido adquiridos, fisuras derivadas de errores de diseño y/o de fabricación que inutilizan la cosa, semillas que no germinan, fertilizantes cuya composición corrosiva afecta una plantación o arbustos frutales de un predio que presentan defectos en sus raíces que obstaculizan su crecimiento, causándose, en todos estos casos, daños al comprador ${ }^{48}$.

Se trata de un medio de tutela que puede acompañar, si el acreedor así lo decide, a las acciones redhibitoria y quanti minoris, o intentarse autónomamente, como lo ha reconocido nuestra Corte Suprema en la última década ${ }^{49}$ invocando el diferente plazo de prescripción a que está sujeta, y la doctrina nacional que ha justificado su procedencia en éste argumento ${ }^{50}$, recurriendo además a su diverso fundamento, supuesto,

${ }^{47}$ De la Maza, Íñigo, Los limites del deber precontractual... cit. (n. 23), pp. 7098.

48 Supuestos todos ellos conocidos por nuestros tribunales. Véase LÓPEZ Díaz, Patricia Verónica, La indemnización de daños por vicios redhibitorios como medio de tutela precontractual autónomo en el Código Civil Chileno: un tópico cuya procedencia y alcance aún permanecen difusos, en Departamento de Derecho Privado Universidad de Concepción (edit.), Manuel Barría (coordinador), Estudios de Derecho Civil XI (Santiago, Thomson Reuters La Ley, 2016), pp. 661-666, notas 10 a 24.

${ }^{49}$ Así ha acontecido desde en Larzabal Beraza con Sociedad Inmobiliaria Talasia de 27 de marzo de 2008 (Corte Suprema, 27 de marzo de 2008, www.vlex.cl, No VLEX-332708178) a la fecha, advirtiéndose como excepción Egon Vyhmesoter Sielbald con Covepa S.A. por la Corte Suprema (Corte Suprema, 30 de noviembre de 2012, www.legalpublishing.cl, $N^{\circ}$ LegalPublishing: CL/JUR/2742/2012). Una visión panorámica en LOPEZ, Patricia, La indemnización de daños por vicios... cit. (n. 48), pp. 661-666, notas 10 a 24.

${ }^{50}$ GuZmán Brito, Alejandro, Sobre la relación entre las acciones de saneamiento de los vicios redhibitorios y las acciones comunes de indemnización, con especial referencia a su prescripción (opinión profesional), en Revista Chilena de Derecho Privado 9 (2007), pp. 115-117 y 119, De la Maza Gazmuri, Ínigo, A propósito del artículo 1861, en Departamento de Derecho Privado Universidad de Concepción (coordinador), Es- 
naturaleza jurídica y finalidad respecto de las acciones edilicias y a la libre opción que el legislador reconoce al comprador en los artículos 1861 y 1933, asentando las bases dogmáticas sobre las cuales ella se erige ${ }^{51}$.

Por consiguiente, en principio, estaríamos ante una indemnización indefectiblemente precontractual que, en cuanto tal, tendría por propósito resarcir el in terés negativo o en la confianza, dejando al acreedor en la misma situación en que se encontraría si no hubiera celebrado el contrato y que, a diferencia de la indemnización por incumplimiento, exige al deudor actuar con dolo o culpa grave, cuyo plazo de prescripción, como lo ha reconocido nuestra doctrina y jurisprudencia reciente, ${ }^{52}$ sería de 5 años. Ciertamente se trata de una indemnización diversa de la contractual, prevista en términos generales en el artículo 1489 y particularmente en los artículos 1553 y 1555 del Código Civil con ocasión del incumplimiento de las obligaciones de hacer y no hacer, toda vez que su fundamento es distinto, el grado de imputabilidad del deudor es mayor que el requerido en la contractual y los argumentos para sustentar su ejercicio exclusivo también difieren, porque el cotejo de la indemnización por incumplimiento se realiza respecto del cumplimiento y la resolución, en cambio aquella por vicios redhibitorios se contrapone a las acciones edilicias que tienen un fundamento, naturaleza jurídica y finalidad que difiere de aquella ${ }^{53}$.

A nuestro juicio, el legislador quiso tipificar indemnizaciones distintas, no sólo por las diferencias apuntadas, sino porque no tendría mucho sentido que hubiera aludido en los artículos 1861, 1933, 2192 y 2203 a la indemnización contenida en los artículos 1553, 1555, 1556, 1558 y 1489, dado que, en tales casos, se hubiera remitido a las reglas generales, como lo hizo en el inciso primero del artículo 1999 a propósito del contrato de confección de obra material. Asentada esta premisa surgen dos interrogantes: En primer lugar, ¿puede optar el acreedor entre una y otra indemnización? Y, en el evento que efectivamente pueda escoger, ¿cuál de las dos le conviene más?

En lo que concierne a la primera de ellas la respuesta es afirmativa, toda

tudios de Derecho Civil V (Santiago, AbeledoPerrot LegalPublishing, 2010), p. 457, nota 10, Oviedo AlBÁN, Jorge, Indemnización de perjuicios por vicios redhibitorios en el Código Civil chileno-colombiano, en Revista Pontificia Universidad Javeriana 129 (2014), pp. 262-266 y LópEZ, Patricia, La indemnización de daños por vicios redhibitorios..., cit. (n. 48), pp. 671-673.

${ }^{51}$ López, Patricia, La indemnización de daños por vicios... cit. (n. 48), pp. 666675.

52 Véase notas 49 y 50.

53 Véase, respectivamente, López, Patricia, La autonomía de la indemnización de daños por incumplimiento..., cit. (n. 1), pp. 279-328 y LÓPEZ, Patricia, La indemnización de daños por vicios... cit. (n. 48), pp. 666-674. 
vez que si bien se ha infringido un deber de información durante esa etapa éste ciertamente se proyecta en el contenido del contrato y determina un cumplimiento defectuoso, pero transitará desde la fase precontractual a la contractual, sólo si el acreedor decide demandarla como tal ${ }^{54}$, esto es, inclinarse por ella. Así acontecerá si, por ejemplo, tiene dificultades para probar el interés negativo ${ }^{55}$. Con todo, si bien este razonamiento es dogmáticamente acertado, tratándose del régimen de las acciones edilicias, nuestros tribunales en ocasiones han invocado el principio de especialidad para desestimar la procedencia de los medios de tutela por incumplimiento ${ }^{56}$, de modo que, aplicando el mismo razonamiento, podría ocurrir que se pronunciaran en igual sentido respecto de la indemnización asociada a ellas, desestimando la elección de la indemnización contractual.

Pues bien, en el evento que nuestros tribunales admitieran derecho del acreedor a escoger entre ambas yle reconocieran la facultad de efectuar la proyección antes mencionada, cabe preguntarse si ésta efectivamente le conviene. Y la respuesta es que le es mucho más provechoso inclinarse por la contractual, dado que la indemnización prevista en el artículo 1861 requiere dolo o culpa grave del deudor y aquellas de los artículos 2192 y 2203 solamente dolo, de modo que el acreedor deberá acreditar en tales supuestos la conducta maliciosa ${ }^{57}$. Distinto es el caso de la pretensión indemnizatoria por inejecución prevista en los artículos 1489, 1553 y 1555 pues como no realiza tal exigencia queda disciplinada por la regla general, cual es el inciso tercero del artículo 1547, de conformidad al cual el incumplimiento se presume culpable ${ }^{58}$.

De hecho, jurisprudencialmente se ha asentado que debe probarse el

${ }^{54}$ López, Patricia, La indemnización de daños por vicios... cit. (n. 48), pp. 680681.

55 Y en el caso que tuviera dificultades para acreditar el daño en el interés negativo podría optar por la indemnización por incumplimiento. Admitiendo esta posibilidad PANTAleón, Fernando, Responsabilidad precontractual: propuestas de regulación para un futuro Código Latinoamericano de Contratos, en Anuario de Derecho Civil 64 (2011) 3, pp. 920-921.

${ }^{56}$ Una visión panorámica en DE LA MAZA, Íñigo, La tutela del comprador frente... cit. (n. 6), pp. 144-145 y 147-148.

${ }^{57}$ Con todo, deberá probarse la culpa grave en aquella del artículo 1861 si se estima que la equiparación del dolo a la culpa grave a que alude el inciso final del artículo 44 del Código Civil es absoluta (BANFI DEL Río, Cristián, La asimilación de la culpa grave al dolo en la responsabilidad contractual en Chile, en Revista Chilena de Derecho 27 (2000) 2, pp. 327-328).

${ }^{58}$ Regla aplicable incluso a las obligaciones de medios y las obligaciones de resultado. Por todos, Peñailillo Arévalo, Daniel, Obligaciones. Teoría general y clasificaciones. La resolución por incumplimiento (Santiago, Editorial Jurídica de Chile, 2003), pp. 228-229. 
dolo negativo del vendedor, precisando que éste no sólo consiste en no dar noticia de los vicios conocidos por éste al comprador sino en que tal omisión esté dirigida a que este último manifieste su voluntad de compra. Como se advierte, la carga de la prueba es excesivamente gravosa para el comprador en comparación a la indemnización por incumplimiento. Esta constatación, denunciada por nuestra doctrina más reciente ${ }^{59}$, constituye un argumento adicional para abogar por el reconocimiento de la opción del acreedor entre la indemnización precontractual y contractual ${ }^{60}$.

c) La falta de objeto del acto o contrato.- Desde antiguo se ha discutido en nuestra doctrina si la falta de objeto acarrea nulidad absoluta o inexistencia del acto o contrato celebrado. En efecto, de un lado se sostuvo que la inexistencia tenía cabida en el Código Civil ${ }^{61}$ aduciendo que si bien no estaba regulada ni mencionada en él existían diversos preceptos de los que podría desprenderse, que el artículo 1682 del Código Civil al aludir a la omisión de algún requisito o formalidad que las leyes prescriben para el valor del ciertos actos o contratos en consideración a la naturaleza de ellos comprendería sólo los requisitos de existencia y que el inciso final de dicho precepto sanciona a los actos de los incapaces absolutos con nulidad absoluta, atendido que éstos pueden aparentar voluntad. De otro lado, se postuló que el Código no la contemplaba, que el artículo 1682 se referiría tanto a los requisitos de existencia como de validez del acto y que su inciso final sanciona a los actos de los incapaces absolutos (esto es, a quienes efectivamente les falta voluntad o no pueden expresarla claramente) con nulidad absoluta y no con inexistencia ${ }^{62}$.

59 Bohle Alar, Alejandra - Contardo GonzÁlez, Juan Ignacio, Criterios jurisprudenciales que determinan los requisitos de aplicación de la indemnización de perjuicios establecida en el artículo 1861 del Código Civil, en ConTARDo GonZález, Juan Ignacio - De la MAZA G., Ínigo, La Compraventa. Estudios (Santiago, Thomson Reuters, 2017), pp. 476-485.

${ }^{60}$ Un fenómeno similar se advierte a propósito de la indemnización prevista en el inciso final del artículo 1814 aplicable al que vendió "a sabiendas" lo que en todo o en una parte considerable no existía.

${ }^{61}$ Rossel Saavedra, Enrique, Teoría de las nulidades (Santiago, Balcells, 1926), pp. 39-81, con especial énfasis en la página 48.

${ }_{62}$ Una síntesis de esta discusión en Rodríguez, Pablo, cit. (n. 3), pp. 68-79, Vial del Río, Víctor, Teoría general del acto jurídico (5a edición, Santiago, Editorial Jurídica de Chile, 2003), pp. 237-245, SAN MarTín, Lilian, cit. (n. 19), pp.754-756 y 762-768 y Ugarte Godoy, José Joaquín, La inexistencia jurídica, en Departamento de Derecho Privado Universidad de Concepción (editor), Barría Paredes, Manuel (coordinador), Estudios de Derecho Civil XI (Santiago, Thomson Reuters, 2016), pp. 817-840. 
Sin embargo, en el último tiempo se han ha formulado contundentes argumentos históricos y de texto para sostener que la nulidad absoluta es la máxima sanción de ineficacia en el Código Civil y que ésta opera de pleno derecho. Así se ha indicado que la historia fidedigna del establecimiento de los artículos 1681 y 1683 permitiría afirmarlo, toda vez que la expresión saneamien to empleada en el artículo 1683 no aludiría a la desaparición del vicio del acto, sino a su plazo de extinción y, la legitimación de éste, sería una consecuencia del transcurso del tiempo. A ello se agrega que el Proyecto de 1842 y el párrafo 36 del Mensaje del Código, arrojarían que para Bello la nulidad relativa rescindía el acto, esto es, lo privaba de efectos, no así la nulidad absoluta, de modo que esta última tendría carácter ipso iure o a u to mático ${ }^{63}$. Finalmente, se ha precisado que existirían distintos preceptos en nuestro Código Civil que permitirían postular este efecto, a propósito de la validación de un título posesorio que en principio fue nulo (arts. $704 \mathrm{~N}^{\circ} 3$ y 705), de las obligaciones naturales nulas (arts. $1470 \mathrm{~N}^{\circ}$ $1 \mathrm{y} \mathrm{N}^{\circ} 3$ ) y sus efectos (art. 2575), de la fuerza obligatoria del contrato (art 1545) y de la regla residual que prevé las causales de nulidad relativa (art. 1683 , inc. final $)^{64}$.

Lo cierto es que más allá de la actual discusión que se ha instalado en el moderno derecho de contratos respecto de si la imposibilidad inicial determina la invalidez y/o incumplimiento del contrato ${ }^{65}$, de conformidad a lo preceptuado en el artículo 1682, la falta de objeto se sitúa en la fase precontractual, sea que constituya una causal de nulidad absoluta o inexistencia. Tal discusión no impide que tal anomalía pueda proyectarse a la fase de ejecución bajo la figura de la resolución por incumplimiento en la causal frustración del interés del acreedor ${ }^{66}$. Piénsese en el caso que el vendedor no entrega al comprador determinadas piezas de aluminio o sólo entrega una parte, toda vez que en tales supuestos no sólo falta el objeto, sino que se verifica la privación de las ganancias que éste esperaba obtener al celebrar el contrato.

Nuevamente surge la pregunta respecto de la conveniencia de efectuar esta proyección para el acreedor. Claro está, como lo hemos precisado en

${ }^{63}$ Baraona, Jorge, cit. (n. 3), pp. 55-62 y 65 y San Martín, Lilian, cit. (n. 19), pp. 760-762, 769-770 y 777-778.

${ }^{64}$ BaraOna, Jorge, cit. (n. 3), pp. 59-62 y SAn Martín, Lilian, cit. (n. 19), pp. 769-770.

${ }^{65}$ Un completo análisis en FENOY PICÓN, Nieves, La revisión del tratamiento de la imposibilidad inicial y del error en los contratos, a través del análisis jurídico de diversos textos jurídicos, en Anuario de Derecho Civil 70 (2017) 2, pp. 473-785.

${ }_{66}$ Un acabado análisis en Mejías, Claudia, El incumplimiento resolutorio... cit. (n. 1), pp. 242-264. 
otro sitio $^{67}$, que la tutela aniquilatoria que la nulidad absoluta y la resolución dispensan al acreedor es asimétrica en cuanto al efecto con el que operan, la restitución de los frutos, la procedencia de la acción reivindicatoria respecto de los terceros y el plazo de prescripción. Y es que resulta indiscutido que la nulidad tiene efecto retroactivo y tal efecto acarrea la restitución de los frutos (salvo que el poseedor esté de buena fe), que la acción reivindicatoria de conformidad al artículo 1689 puede intentarse contra cualquier tercer poseedor y el plazo de prescripción, si se estima que el artículo 1682 consagra su extinción por esta vía -y no opera de pleno derecho ${ }^{68}-$, es de 10 años desde la celebración del acto o contrato. El alcance de la tutela aniquilatoria es distinto en la resolución, toda vez que actualmente se ha postulado que los efectos de ésta se despliegan hacia el futuro operando una liquidación del contrato ${ }^{69}$, la regla general según el artículo 1688 es que los frutos no se restituyen, a menos que los contratantes, donante, testador o la ley así lo dispongan, la acción reivindicatoria, de conformidad a los artículos 1490 y 1491 , no procedería respecto del tercer poseedor de mala $\mathrm{fe}^{70}$ y el plazo de prescripción sería de 5 años desde la celebración del acto o contrato.

${ }^{67}$ LÓPEZ, Patricia, Tutela precontractual versus tutela contractual... cit. (n. 38).

${ }^{68}$ Fabres, José Clemente, De la nulidad y la rescisión en Obras Completas, Vol. III (Santiago, Imprenta Cervantes, 1908), pp. 145-170, BARAONA, Jorge, cit. (n. 3), pp. 50-63, Alcalde Silva, Jaime, La rescisión en el Código Civil chileno, en Departamento de Derecho Privado Universidad de Concepción (coordinador), Estudios de Derecho Civil V (Santiago, AbeledoPerrot LegalPublishing, 2010), p. 69, SAN MARTín, Lilian, cit. (n. 19), pp. 769-770 y Rodríguez, Pablo, cit. (n. 3), pp. 129-135, tratándose de la nulidad radical.

${ }^{69}$ Pizarro Wilson, Carlos, Contra el efecto retroactivo... cit. (n. 1), pp. 457-460; Contardo, Juan, Indemnización y resolución..., cit. (n. 1), pp. 317-334, AlCalde Silva, Jaime, Bases para una sistematización de los efectos de la resolución por incumplimiento en Vidal OLivares, Álvaro - Severin Fuster, Gonzalo - Mejías Alonzo, Claudia (editores), Estudios de Derecho Civil X (Santiago, Thomson Reuters La Ley, 2015), pp. 591-594 y MejíAs Alonzo, Claudia Carolina, Una revisión crítica de los efectos de la resolución por incumplimiento y una propuesta de solución, en Revista Ius et Praxis año 22 (2016) 1, pp. 271-322.

${ }^{70}$ Con todo, dejamos constancia que la regla relativa a la restitución de los frutos y la procedencia de la acción reivindicatoria respecto del tercer poseedor de mala fe se extraen del régimen de la condición resolutoria tácita y que nuestra doctrina, ha sugerido desprenderse de ellas y crear un régimen especial aplicable a la resolución (AlCAlde, Jaime, Bases para una sistematización... cit. (n. 69), pp. 592-600 y MejíAS, Claudia, Una revisión crítica de los efectos..., cit. (n. 69), pp. 276, 287-288 y 314. Abordando este desafío, AlCALDE SILVA, Jaime, El contenido de la restitución derivada de la resolución por incumplimiento, en Libro Homenaje a Leslie Tomasello, en prensa. Agradezco al autor la gentileza de haberme facilitado dicho manuscrito. 
Sin embargo, el factor más relevante que puede inclinar al acreedor por demandar la nulidad absoluta y desestimar la resolución es la posibilidad que tiene el deudor de oponer la excepción anómala de pago regulada en el artículo 310 del Código de Procedimiento Civil durante toda la secuela del juicio, toda vez que ésta enervará la acción resolutoria, conculcando la opción del acreedor. Miradas las cosas desde esta perspectiva, mientras no se adopte la modalidad de resolución extrajudicial entre nosotros ${ }^{71}$, la nulidad resulta más adecuada para el acreedor que la resolución, constatación que nos permite abogar, al menos en esta hipótesis, por la conveniencia de la tutela precontractual.

d) El error y dolo vicios del consentimiento.- El último supuesto en que se advierte una relación de proyección-absorción entre la tutela precontractual y contractual es el error y dolo como vicios del consentimiento. Conceptualmente son diversos, pues el error constituye una falsa representación de la realidad y el dolo una maquinación fraudulenta destinada a inducir al otro a celebrar un determinado acto o contrato ${ }^{72}$. Sin embargo, existe una razón que justifica tratarlos conjuntamente para efectos de esta investigación: ambos constituyen mecanismos o dispositivos de distribución de riesgos de la información defectuosa ${ }^{73}$.

Claro está que ambos, en cuanto vicios del consentimiento, activan la nulidad relativa. Pero de la misma forma resulta evidente que, al igual que la falta de objeto, pueden configurar la causal de resolución por incumplimiento frustración del interés del acreedor. Y es que la anomalía o disconformidad que determina la procedencia de la nulidad relativa, puede, a la vez, significar para el acreedor la pérdida de los beneficios que esperaba obtener con la celebración del acto o contrato. Piénsese en la diversa sustancia de la cosa entregada o en la ausencia de las cualidades

${ }^{71}$ Como lo revelan los artículos 9:303 de los PECL, III.- 3:507 del DCFR, 7.3.2 de los PICC, 1199 inciso segundo de la PME, 518-13.2 de la PAPDC y en el artículo 1226 del Code, después de la reforma introducida por la Ordenanza de 10 de febrero de 2016 que ha seguido este modelo.

${ }^{72} \mathrm{Y}$ no necesariamente un conjunto de ellas: vid. De la MAZA Gazmuri, Íñigo, Afirmaciones conscientemente falsas y mediana diligencia. A propósito de la sentencia de la Corte Suprema de fecha 4 de abril de 2016, en Revista de Derecho Universidad Católica del Norte 23 (2016) 2, pp. 318-321.

73 Como lo ha sugerido Morales, Antonio, ¿Es posible construir un sistema precontractual..., cit. (n. 4), p. 407 y, entre nosotros De la MAZA GAZMURI, Íñigo, La distribución del riesgo y la buena fe. A propósito del error, el dolo y los deberes precontractuales de información, Revista de Derecho de la Pontificia Universidad Católica de Valparaiso 37 (2011), pp. 115 y 132. 
esenciales o accidentales que una de las partes tuvo en consideración al momento de contratar.

Nuestra Corte Suprema ha resuelto casos en que los supuestos de hecho revelan el fenómeno que venimos comentando a propósito del error sustancial regulado en el artículo 1454 del Código Civil. Sin embargo, si la falsa representación de las cualidades presupuestas de la cosa que referiremos a continuación fuera provocada por una parte con la intención de inducir a la otra a contratar, claramente podría alegar nulidad por dolo a partir del inciso primero del artículo 1458. Sirva de ejemplo Consorcio Transportes Trancura con Tocale ${ }^{74}$ en que el comprador demandó la nulidad del contrato, invocando error sustancial, dado que los camiones vendidos fueron fabricados en años distintos a los que estipulaba el contrato. O Sociedad Agrícola Santa Anita con Faenadora El Milagro S.A. en que la ausencia de la cualidad esencial en que el comprador fundó el error sustancial consistió en la toxicidad de la carne de los cerdos adquiridos que le impidió faenarlos y exportarla para su consumo $^{75}$. El fenómeno inverso se aprecia en Glide Inversiones Ltda. con Compañías de Inversiones y Desarrollo Sur S.A., en que el arrendatario demandó la terminación del contrato con indemnización de daños, porque si bien se estipuló que destinaría el predio a explotar una cancha de minigolf no fue posible, pues no se encontraba urbanizado ni tenía permiso de edificación y recepción final y, además, una franja de éste estaba sujeta a utilidad pública ${ }^{76}$.

Como ya lo hemos asentado a propósito de la falta de objeto, el acreedor puede proyectar el supuesto de hecho que determina la procedencia de tales vicios y alegar la resolución por incumplimiento. $\mathrm{Y}$, como también lo consignamos más arriba, la decisión de efectuar dicha operación residirá en el alcance de la tutela aniquilatoria que pretenda obtener y en la necesidad de evitar que su pretensión de desvincularse del contrato sea enervada por la excepción anómala de pago, deviniendo la nulidad relativa, al menos en este supuesto, en un medio de tutela más eficaz que la resolución, si se postula que ella requiere declaración judicial, a partir de lo preceptuado

74 Consorcio Transportes Trancura Ltda. con Tocale Tuna, Romilio: Corte Suprema, 19 de enero de 2010 (casación en el fondo), en www.microjuris.com, $N^{\circ}$ MJCH_MJJ22895.

75 Sociedad Agrícola Santa Anita con Faenadora El Milagro S.A.: Corte Suprema, 9 de diciembre de 2015 (casación en el fondo), en www.vlex.com, N VLEX589170582 .

76 Glide Inversiones Ltda. con Compañia de Inversiones y Desarrollo Sur S.A.: Corte Suprema, 19 de enero de 2008 (casación en el fondo), en www.vlex.com, $\mathrm{N}^{\circ}$ VLEX 41113399. 
en los artículos 1489, 1873, 1878 y 1879 del Código Civil. Nuestra conclusión, en cambio, sería distinta si, como hemos sugerido en otro sitio ${ }^{77}$, se le atribuyera un carácter extrajudicial, entendiendo que ella opera por una declaración de voluntad unilateral y recepticia representada, por ejemplo, por una notificación realizada a través de medios idóneos y eficaces para que el destinatario tome conocimiento de aquella o se admita la modalidad bilateral en que ambas partes procedan a constatarla.

\section{Las anomalias o disconformidades que no pueden proyectarse desde la} fase precontractual a la contractual

De lo expresado hasta acá podría pensarse que prácticamente la totalidad de las anomalías o disconformidades acaecidas en la fase precontractual pueden proyectarse a la contractual. Pero si se analizan éstas con mayor detención es posible advertir que existen al menos dos casos en que ello no ocurre y que, por lo mismo, vienen a justificar esta etapa del iter contractual. Se trata de la ruptura injustificada de las tratativas preliminares y la fuerza como vicio del consentimiento. En este mismo orden los examinaremos, deteniéndonos particularmente en el último por la complejidad que éste reviste.

a) La ruptura injustificada de las tratativas preliminares.-Como es bien sabido, el retiro injustificado de los tratos o negociaciones preliminares constituye indefectiblemente un supuesto de responsabilidad precontractual, cuya procedencia, fundamento, naturaleza jurídica, requisitos y daños indemnizables se encuentra contundentemente asentados en nuestra dogmática $^{78}$. Con todo, y como lo hemos consignado precedentemente

77 López, Patricia, Por la articulación de un sistema de medios.... cit. (n. 4), pp. 476-477.

${ }^{78}$ Rosende, Hugo, cit. (n. 3), Domínguez Águila, Ramón, Comentario de jurisprudencia: Responsabilidad precontractual. Principio de buena fe, aplicación del art. 1546 solo a la ejecución del contrato. Casación en el fondo por infracción de ley, en Revista de Derecho (Universidad de Concepción) 217-218 (2005), pp. 305-311, BARros, Enrique, cit. (n. 24), pp. 1014 a 1041, ZuloAga Ríos, Isabel Margarita, Teoría de la responsabilidad precontractual. Aplicaciones en la formación del consentimiento de los contratos (Santiago, LexisNexis, 2006), De LA MAZA GAZMURI, Ínigo, El retiro unilateral como un caso de responsabilidad precontractual en DE LA MAZA GAZMURI, Íñigo (editor), Cuaderno de Análisis Jurídico III (Santiago, Ediciones Universidad Diego Portales, 2006), pp. 131-158, Barrientos Zamorano, Marcelo, Daños y deberes en las tratativas preliminares de un contrato (Santiago, LegalPublishing, 2008), CELEDÓN Förster, Rosario-Silberman VeszPremi, Patricia, Responsabilidad precontractual por ruptura de negociaciones contractuales (Santiago, Editorial Jurídica de Chile, 2010), SAN MARTín NeIRA, Lilian, Responsabilidad precontractual por ruptura injustificada 
a propósito de la relación de conexión entre la tutela precontractual y contractual, en ocasiones la jurisprudencia no ha delineado correctamente sus contornos ${ }^{79}$.

De otro lado, se ha admitido que se rige por las normas de la responsabilidad civil extracontractual, esto es, aquellas contenidas en el Título 35 del Libro IV del Código Civil ${ }^{80}$ y que su fundamento mediato se encontraría en la buena fe, pero que el in mediato radicaría en la infracción del deber de lealtad de quien se retira injustificadamente, toda vez que ha generado en la otra parte una confianza razonable que el contrato se celebraría $^{81}$. Asimismo, se ha establecido como requisitos de procedencia de esta pretensión indemnizatoria, la creación de una razonable confianza en la conclusión o perfeccionamiento del contrato proyectado, el carácter injustificado e intempestivo de la ruptura, el daño en el patrimonio del otro contratante y la existencia de una relación de causalidad entre tal daño y la confianza que fue promovida y resultó defraudada por quien abandona las negociaciones ${ }^{82}$.

La aplicación de dicho régimen ha determinado que se discuta si efectivamente existe responsabilidad precontractual o ésta puede reconducirse a la extracontractual. Sin embargo, como lo hemos apuntado en otro sitio $^{83}$, existen al menos dos consideraciones que nos permiten abogar

de negociaciones. Corte Suprema, Rol 1872/2010, en Revista Chilena de Derecho 40 (2013) 1, pp. 315-322 y López Díaz, Patricia Verónica, La ruptura de las tratativas preliminares como una justificada excepción al principio de libertad contractual y un particular supuesto de indemnización precontractual, en Estudios de Derecho de Contratos en Homenaje a Antonio Manuel Morales Moreno, en prensa.

${ }^{79}$ Así ha ocurrido en Inmobiliaria Los Canelos S.A. con Inmobiliaria e Inversiones Sevilla Ltda., cit. (n. 30) y Lange Haensgen con Ibáñez Santa María, cit. (n. 33) y Urrea Puentes con Corpbanca: Corte Suprema, 12 de abril de 2012 (casación en el fondo), en www.vlex.com, $\mathrm{N}^{\circ}$ VLEX 436253870, en que el tribunal desde el considerando cuarto al noveno transita entre la ruptura de las tratativas preliminares, el cierre de negocios y el incumplimiento de la convención perfeccionada por la aceptación de la oferta.

${ }^{80}$ Con excepción de Rodríguez Grez, Pablo, Nuevas tendencias de la responsabilidad (Santiago, AbeledoPerrot LegalPublishing, 2011), p. 198 que estima que su fundamento se encuentra en la ley.

${ }^{81}$ Una visión integradora de estos tres fundamentos en López, Patricia, La ruptura de las tratativas preliminares... cit. (n. 78).

82 Véase autores indicados en la nota 78.

${ }^{83}$ LÓPEz DíAz, Patricia Verónica, La indemnización precontractual y contractual: divergencias y eventuales zonas de confluencia" en BARRÍa Díaz, Rodrigo - FerRANTE, Alfredo - San Martín Neira, Lilian C., Presente y Futuro de la Responsabilidad Civil. Actas del Congreso Internacional de 3 y 4 de noviembre de 2016, Santiago de Chile (Santiago, Reuters, 2017), pp. 122-123. 
por su existencia como una categoría particular de aquella: el contacto negocial y la noción de in terés negativo como partida indemnizable. $Y$ es que tratándose de un ilícito extracontractual tal contacto no existe, toda vez que la víctima y victimario son, por regla general, extraños absolutos (constatación que la aproxima a la responsabilidad contractual) y no se ha celebrado contrato alguno o habiéndose celebrado, quedó privado de efectos (premisa que la distancia de aquella que requiere un contrato válido). De otro lado, y precisamente, como consecuencia de tal particularidad, el interés indemnizable, por regla general, es el negativo, porque éste persigue dejar al acreedor en la situación que se habría encontrado de no haber contratado. Pues bien, esta medida del interés resarcible no se identifica con aquella del ilícito extracontractual propiamente tal, dado que, en dicho supuesto, no se proyectó la celebración de ningún contrato, de modo que tal cotejo no podría realizarse.

De allí que no pueda proyectarse el daño acaecido en la etapa precontractual a la de inejecución del contrato, toda vez que el contrato no se ha celebrado. En consecuencia, la indemnización debe perseguir la reparación del interés negativo o en la confianza, procediendo en forma autónoma o exclusiva y no del interés positivo o en el cumplimiento. Con todo, en el último tiempo el profesor Antonio Manuel Morales Moreno ha sostenido que, excepcionalmente la indemnización derivada de la ruptura injustificada de las tratativas preliminares podría cubrir este interés si ella tiene por propósito privar al otro negociante del beneficio cierto que la celebración del contrato le podía reportar ${ }^{84}$, de modo que, de admitirse esta hipótesis, estaríamos ante un supuesto de proyección del daño precontractual a la fase de ejecución o cumplimiento.

b) La fuerza vicio del consentimiento.- Como es bien sabido, la fuerza moral o intimidación constituye un vicio del consentimiento contemplado en el artículo 1451 y regulado en los artículos 1456 y 1457 del Código Civil que exigen que tal amenaza de un mal futuro sea grave, injusta y determinante en la voluntad de celebrar un contrato, evidenciando que nuestro Código recoge una concepción subjetiva tratándose de la gravedad de la fuerza. En efecto, la entidad de la amenaza o gravedad, al igual como acontece en el $\operatorname{Code}^{85}$ y en el artículo 1267 del Código Civil español y sus

${ }^{84}$ Morales Moreno, Antonio Manuel, Los Principios latinoamericanos de derecho de los contratos. Un debate abierto sobre grandes cuestiones juridicas de la contratación, Anuario de Derecho Civil 67 (2014) 1, p. 231.

${ }^{85}$ Incluso después de la Ordenanza № 2016-131 de 10 de febrero de 2016 que mantiene esa exigencia en el artículo 1140. 
Propuestas de modernización ${ }^{86}$ se configura si existe "una impresión fuerte o justo temor", lo que contrasta con la tendencia objetivizadora de los instrumentos europeos de armonización contractual que ha reemplazado este requisito por la "falta de una alternativa razonable" 87 , más acorde con una noción objetiva de los vicios del consentimiento y una concepción económica del contrato ${ }^{88}$.

Lo cierto es que más allá de esta discusión, al existir fuerza vicio del consentimiento nos situamos en un escenario absolutamente diferente al del error y el dolo, dado que ésta no constituye un mecanismo de distribución de riesgos de la información defectuosa ${ }^{89}$, no pudiendo proyectarse desde la fase precontractual a la contractual, pues el supuesto de hecho no puede subsumirse en algún medio de tutela por incumplimiento. En efecto, la amenaza de un mal futuro grave, injusto y determinante regulada en los artículos 1456 y 1457 no resulta absorbible por la resolución, el cumplimiento específico, la indemnización de daños o la rebaja del precio. La explicación probablemente se encuentre en el hecho que la fuerza, en la concepción clásica que ha prevalecido en nuestra dogmática, evidencia la ausencia de una voluntad libre y en la más moderna, acogida por la doctrina comparada, se traduce en el aprovechamiento de la situación en que se encuentra el otro contratante; en tanto, el error y el dolo, que tradicionalmente se concibieron como vicios cuyo fundamento se encontraba en la ausencia de co nocimien to del otro contratante, actualmente descansan en la ausencia de la correcta información proporcionada para celebrar el contrato ${ }^{90}$. Dicho de otra forma, no se trata de un problema

${ }^{86}$ Así lo revelan el inciso tercero del artículo 1299 de la Propuesta de Modernización del Código Civil en materia de obligaciones y contratos (PME) y el artículo 527-8 de la Propuesta de Código Civil relativa a los Libros Quinto y Sexto elaborada por la Asociación de profesores de Derecho Civil español de 2016 (PAPDC) que si bien adiciona como requisito la "falta de otra alternativa razonable", mantiene la exigencia de que la amenaza provoque "un temor racional y fundado".

${ }^{87}$ Una visión panorámica de ambas tendencias en Solé Feliú, Josep, La intimidación o amenaza como vicio del consentimiento contractual: textos, principios europeos y propuestas de reforma en España, en Indret, Revista para el Análisis del derecho (2016) 4, pp. 16 y 19 - 22, disponible en http://www.indret.com/pdf/1261_es.pdf.

${ }^{88}$ Del Olmo García, Pedro, La amenaza de incumplir un contrato como vicio del consentimiento (Valencia, Tirant lo Blanch, 2003), p. 146.

${ }^{89}$ Como lo ha sugerido Morales, Antonio, ¿Es posible construir un sistema precontractual...?, cit. (n. 4), p. 407 y, entre nosotros De LA MAZA GAZMURI, Íñigo, La distribución del riesgo... cit. (n. 73), pp. 115 y 132.

${ }^{90}$ Otra perspectiva útil para diferenciarlos es aquella que postula que el error pertenece al ámbito de control de la parte que lo sufre, asignándole a ella dicho riesgo, a diferencia de la fuerza y el dolo en que la declaración se realiza bajo la influencia de un ilícito (Barros Bourie, Enrique, La doctrina de la fuerza en el marco de la 
relativo a la información necesaria para concluirlo, sino de la libertad para tal efecto, de modo tal que si ésta ha faltado no puede proyectarse a la fase de ejecución, solicitando el cumplimiento o rebaja del precio (porque es un contrato no querido), la resolución (no ha existido frustración del interés del acreedor, ya que no perdió el beneficio que esperaba obtener del contrato, toda vez que nunca tuvo tal expectativa, pues fue coaccionado a celebrarlo) o la indemnización por inejecución (porque no quiere que éste subsista ni se extinga ${ }^{91}$, sino ubicarse en la fase anterior a éste).

Sin embargo, es perfectamente posible que una de las partes del contrato, una vez celebrado éste, amenace con incumplirlo con el propósito de forzar su renegociación o adaptación, supuesto en el cual, la víctima de esta amenaza podrá resistirla, alegando vicio del consentimiento, o admitirla y negociar los términos del contrato, en el evento que, efectivamente, haya existido una alteración sobrevenida de las circunstancias que alteren la base del negocio. Este supuesto ha sido analizado en el derecho comparado, concluyéndose, como lo ha apuntado correctamente Del $\mathrm{Olmo}^{92}$, que la amenaza de incumplir un contrato puede situarnos ante tres lados de un triángulo: la cláusula rebuc sic standibus, la renegociación y la intimidación vicio. En efecto, en algunos supuestos tal amenaza, que el profesor Enrique Barros ha calificadocomo fuerza económica ${ }^{93}$, no constituye un vicio del consentimiento, sino el anuncio de algo inevitable que es una consecuencia de un suceso imprevisible que dificulta el cumplimiento,

revisión contemporánea de la doctrina voluntarista del contrato, en DEPARTAMENTO DE Derecho Privado Universidad de Concepción (editor), Barría Paredes, Manuel (coordinador), Estudios de Derecho Civil XI (Santiago, Thomson Reuters, 2016), pp. 486-487).

${ }^{91}$ Sobre ambos efectos véase LÓPEZ, Patricia, La autonomía de la indemnización de daños por incumplimiento... cit. (n. 1), pp. 344-356.

92 Del Olmo García, Pedro, La cláusula "rebus", la renegociación de los contratos y la intimidación/vicio: tres lados de un triángulo, en Hornero MÉndez, César- EsPejo Lerdo de Tejada, Manuel-Oliva Blázquez, Francisco (directores), Murga FerNÁNDEZ, Juan Pablo (coordinador), Derecho de contratos: Nuevos escenarios y nuevas propuestas (Madrid, Thomson Reuters Aranzadi, 2016), pp. 421-436.

${ }_{93}$ Para graficar aquella amenaza de hacer valer ilícitamente una posición de poder para causar un daño patrimonial severo a la contraparte, quien para evitarlo accede a consentir el contrato (BARROS BOURIE, Enrique, Fuerza económica y abuso de posición de debilidad de la contraparte en el desarrollo jurisprudencial y doctrinario del derecho de contratos, en Corral Talciani, Hernán - Manterola Domínguez, Pablo (editores), Estudios de Derecho Civil XII (Santiago, Thomson Reuters, 2017), pp. 294-299). 
hipótesis que justifica la admisibilidad e incorporación al contrato de una cláusula rebuc sic standibus ${ }^{94}$ que permita a las partes perseverar en é $1^{95}$.

Piénsese, por ejemplo, en un equipo de jugadores de elite que amenazan con iniciar una huelga si el dueño del club deportivo al que pertenece no les paga un bono mucho más elevado que el acordado para el evento que ganaran los cuatro últimos partidos de la temporada (caso 1) ${ }^{96}$. Otro tanto acontecería si un grupo de pescadores de salmón, una vez apartados del puerto en que fueron contratados y, a sabiendas, que el retorno a éste es muy oneroso y que su empleador por encontrarse en alta mar no puede contratar a otros, lo amenazan con disminuir el ritmo de trabajo si no le sube sus salarios (caso 2) ${ }^{97}$. Un fenómeno similar podría presentarse en el evento que un Astillero se obligue a construir un buque a cambio de un precio fijo y como consecuencia de las fluctuaciones monetarias el deudor experimenta pérdidas económicas que lo llevan a amenazar con incumplir el contrato, a menos que el comprador aceptara un incremento del precio de un $10 \%$ (caso 3$)^{98}$. Finalmente, estaremos ante un supuesto semejante si después de que una empresa contrató a otra para que fabricara piezas especiales para ensamblarlas en una maquinaria que debe entregar a un tercero, ésta última amenaza con no hacerlo si no se elimina la cláusula penal moratoria establecida en su contra, exigiendo además que se estipule la renuncia a dirigir cualquier reclamación en su contra ${ }^{99}$ (caso 4).

La pregunta que surge es si efectivamente se configura un vicio del

${ }^{94}$ Un completo estudio de esta cláusula en Orduña Moreno, Francisco JavierMartínez Velencoso, Luz María, La moderna configuración de la cláusula rebus sic stantibus. Desarrollo de la nueva doctrina jurisprudencial aplicable y derecho comparado (2a edición, Navarra, Civitas Thomson Reuters, 2017).

95 Del Olmo García, Pedro, La renegociación de los contratos bajo amenaza (Un comentario a la STS de 29 de julio de 2013), Anuario de Derecho Civil 67 (2014) 1, p. 325 y SolÉ, Josep, cit. (n. 87), p. 16.

${ }^{96}$ Ejemplo citado en UNIDROIT, InSTITUTO INTERNACIONAL PARA LA UNIFICAción del Derecho Privado, en Garro, A. M. (director), Rodríguez Olmos, Javier Mauricio. Perales Viscasillas, Pilar (colaboradores), Principios UNIDROIT sobre los contratos comerciales internacionales (Madrid, Ediciones UNIDROIT, 2010), p. 116.

${ }^{97}$ Se trata del caso Alaska Packers' Ass'n v. Domenico de 1902, comentado por Del Olmo, Pedro, La amenaza de incumplir un contrato... cit. (n. 88), pp. 74, 133, 134 y 137.

${ }_{98}$ Ejemplo citado en Lando, Ole - Beale, Hugh, Principios de derecho contractual europeo. Partes Iy II (traducción castellana de Pilar Barres Benlloch, José Embid Irujo, Fernando Martínez Sanz, Madrid, Colegios Notariales de España, 2003), pp. 369-370.

99 Este supuesto se presentó en "Zincobre con Difamasa” resuelto por el Tribunal Supremo Español el 29 de julio de 2013, comentado en Del Olmo, Pedro, La renegociación de los contratos... cit. (n. 95), pp. 313-328. 
consentimiento. Los comentaristas de los Principios UNIDROIT sobre Contratos Comerciales Internacionales (PICC) y de los Principios Europeos de Derecho de los Contratos (PECL), a partir de los artículos 3.2.6 de los PICC y 4:108 de los PECL, así lo han estimado aun cuando éstos se refieren a la intimidación para celebrar el contrato, mas no para concluirlo ${ }^{100}$. Lo cierto es que, un análisis más detenido revela que la amenaza de incumplir un contrato podría reconducirse a un supuesto de voluntad viciada, pero también podría justificarse porque ha existido una alteración sobrevenida de las circunstancias. De allí que sea relevante acudir a determinados factores para determinar las consecuencias jurídicas de tal amenaza. Tales son la buena o mala fe de quien amenazó incumplir para renegociar en beneficio propio los términos del contrato, el carácter abusivo o desproporcionado del beneficio obtenido por quien efectuó la amenaza, la existencia de otras alternativas jurídicas y de mercado razonables para que el amenazado pueda enfrentar la presión, la inadecuación de los medios de tutela por incumplimiento, la gravedad del mal amenazado y la actitud de la víctima ${ }^{101}$.

El factor que ha suscitado mayor discusión en la dogmática comparada es aquel que se refiere a la existencia de otra alternativa razonable, entendiendo que ésta debe significar un valor similar a la prestación inicialmente pactada, sugiriéndose que ella tiene lugar en dos supuestos. El primero consiste en recurrir a alternativas extrajurídicas o de mercado y se verifica si existen en éste otros recursos o proveedores alternativos al que el amenazado puede acceder sin coste excesivo. El segundo, en tanto, tiene lugar cuando se acude a alternativas jurídicas, esto es, a otros instrumentos jurídicos que le permitan enfrentar la amenaza, como acontecería si exigiera el cumplimiento específico del contrato ${ }^{102}$. El problema que se presenta es dilucidar en qué caso no puede recurrirse a una alternativa jurídica, pues ello no acontece si el amenazado pretende ahorrar tiempo o sostiene que el recurso a un medio de tutela puede significarle una satisfacción tardía ${ }^{103}$, sino cuando dichos medios resultan inadecuados, lo que ha obligado a la doctrina a recurrir a una cláusula general

100 UNIDROIT, cit. (n. 95), p. 116 y Lando, Ole - BeALE, Hugh, cit. (n. 98), pp. 369-370.

${ }^{101}$ Un análisis de todos ellos en Del Olmo García, Pedro, La amenaza de incumplir un contrato... cit. (n. 88), pp. 133-149. Una enunciación similar en SOLÉ, Josep, cit. (n. 87), p. 17.

102 Del Olmo García, Pedro, La amenaza de incumplir un contrato... cit. (n. 88), pp. 133-146. Una idea similar en Solé, Josep, cit. (n. 87), p. 21.

${ }^{103}$ En contra Carrasco Perera, Ángel, Derecho de contratos (2 $2^{a}$ edición actualizada y revisada, Navarra, Aranzadi Thomson Reuters, Cizur Menor, 2017), p. 384. 
que aglutine tales supuestos. A tal efecto, el profesor Pedro Del Olmo ha sugerido que tal insuficiencia tendría lugar si el amenazado no puede evitar el daño especial difícilmente indemnizable que sufriría por el incumplimiento que amenaza el deudor, como acontecería tratándose del daño a la imagen frente a sus clientes o al peligro de verse expuesto a la resolución del contrato celebrado con un tercero y a la aplicación de la cláusula penal prevista para tal supuesto ${ }^{104}$. Un fenómeno similar se advierte si se trata de piezas especialmente fabricadas o servicios especialísimos que sólo el deudor puede prestar, dado que en tal caso, aunque resuelva el contrato no encontrará otra alternativa en el mercado. De otro lado, el cumplimiento específico podría ser inútil si la prestación debe ejecutarse en un tiempo breve. Y finalmente, puede ocurrir que la indemnización no alcance a cubrir los daños que causa el incumplimiento atendido el ámbito de protección del contrato ${ }^{105}$.

La ausencia de una alternativa razo nable permitirá determinar si ha existido fuerza vicio del consentimiento, facultando a la víctima anular el contrato; en cambio, su existencia le impedirá desvincularse de éste. Pues bien, si consideramos los factores antes enunciados, podemos concluir que, en tres de los supuestos que hemos referido, no existían alternativas extrajurídicas ni jurídicas razonables. En efecto, en el caso de los jugadores (caso 1), la huelga constituía una amenaza grave e inminente para la reputación y situación económica del dueño del club deportivo, porque sin esos jugadores el equipo descendería automáticamente a la categoría inferior ${ }^{106}$. Tratándose de los pescadores (caso 2), el empleador, no podía sino acceder a la solicitud de éstos, pues atendida su ubicación era más oneroso regresar a puerto para contratar a otros, diluyéndose la inversión de haberse desplazado a una zona extrema en la época de pesca del salmón ${ }^{107}$. Otro tanto acontecería con las maquinarias (caso 4), porque no existían otras similares en el mercado y entablar un juicio para obtener el cumplimiento no tenía sentido, porque estaba contra el tiempo ${ }^{108}$.

${ }^{104}$ Del Olmo, Pedro, La amenaza de incumplir un contrato..., cit. (n. 88), pp. 141-146 y Del Olmo, Pedro, La renegociación de los contratos... cit. (n. 95), p. 323.

${ }^{105}$ Del Olmo, Pedro, La renegociación de los contratos... cit. (n. 95), p. 323. Un análisis más ambicioso de la inadecuación de los medios de tutela en Del Olmo, Pedro, La amenaza de incumplir un contrato..., cit. (n. 88), pp. 141-146. Destacando la eventual insuficiencia de la indemnización BARRos, Enrique, Fuerza económica y abuso de posición..., cit. (n. 93), p. 296.

106 Unidroit, cit. (n. 96), p. 116.

107 Del Olmo, Pedro, La amenaza de incumplir un contrato... cit. (n. 88), pp. 134 y 137.

${ }^{108}$ Del Olmo, Pedro, La renegociación de los contratos... cit. (n. 95), p. 328. 
Distinto es el supuesto de construcción del buque (caso 3), dado que, en tal caso, el referido Astillero tiene la alternativa de renegociar el contrato.

El enfoque que hemos venido refiriendo no ha sido explorado en nuestra civilística, pues no se ha sugerido una relectura de la gravedad de la fuerza ni los tribunales nacionales han acogido un criterio similar, a diferencia de lo que ha ocurrido, por ejemplo, con el Tribunal Supremo Español, a pesar que el artículo 1267 del Código Civil es muy similar a nuestro artículo $1456^{109}$. Pues bien, en el evento que en el futuro llegara a estimarse que la amenaza de incumplir un contrato configura un vicio del consentimiento o se modificara nuestro Código en tal sentido, estaremos ante un supuesto en que la fuerza no acaece en la fase de formación del contrato, esto es, al momento de su celebración, sino en la de su ejecución y, por lo mismo, a pesar del momento del iter contractual en que se presenta, podría desplazarnos a un problema de validez del acuerdo de modificación del contrato original, toda vez que los medios de tutela por incumplimiento no constituyen una alternativa razonable para el acreedor, pues resultan inadecuados. Se trataría, en consecuencia, de una relación de proyección distinta a la que hemos analizado en este acápite y que denominaremos proyección inversa, toda vez que acaeciendo la anomalía exclusivamente en la fase de cumplimiento es posible desplazarla a la fase anterior e invalidar dicha modificación contractual o acuerdo novatorio celebrado bajo intimidación.

\section{CONCLUSIONES}

De lo expresado en los párrafos precedentes es posible arribar a las siguientes conclusiones:

a) Existen dos relaciones entre la tutela precontractual y contractual que el acreedor debe conocer para delimitar los contornos entre ambas y diseñar su estrategia de protección frente anomalías o disconformidades suscitadas en la fase precontractual, se proyecten o no a la contractual: la relación de conexión y la relación de proyección-absorción.

b) La relación de conexión le permite advertir los contornos de la fase precontractual y contractual en los contratos preparatorios, evidenciando que ellos constituyen un híbrido que se sitúa en ambas y que, por lo mismo, obliga a calificar jurídicamente la etapa en que la anomalía se presenta para determinar correctamente el estatuto jurídico aplicable,

109 Un análisis panorámico en Del Olmo, Pedro, La renegociación de los contratos..., cit. (n. 95), pp. 313-328 y en lo que concierne al Common Law y el derecho francés véase Barros, Enrique, Fuerza económica y abuso de posición... cit. (n. 93), pp. 295-298. 
evitando desplazar la ausencia de un requisito de configuración a la fase de incumplimiento o calificar como contrato de promesa el consentimien to para celebrarlo y alegar su incumplimiento.

c) La relación de proyección-absorción tiene lugar en aquellos casos en que el acreedor ha decidido desplazar la tutela que el legislador le otorga en la fase precontractual a la contractual, inclinándose por esta última, lo que puede advertirse con ocasión de la vulneración de las obligaciones de advertencia, la existencia de vicios redhibitorios, la falta de objeto del acto o contrato, el error y dolo vicio y, en sentido inverso, tratándose de la amenaza de incumplir un contrato si se configurara como un supuesto de fuerza vicio.

d) El análisis de ambas relaciones permite establecer que existen supuestos en que el acreedor no podrá optar entre la tutela precontractual y la tutela contractual y otros en que ello es posible. En el primer grupo se encuentra el contrato preparatorio frustrado que sólo genera responsabilidad precontractual, el incumplimiento de un contrato preparatorio perfecto que activa exclusivamente la responsabilidad contractual, la ruptura injustificada de las tratativas preliminares que determina la procedencia de la indemnización precontractual y el contrato viciado por fuerza que constituye una causal exclusiva de nulidad relativa. En el segundo, en cambio, destacan la infracción de las obligaciones de advertencia, la existencia de vicios redhibitorios, el contrato al que falta objeto y el contrato viciado por error o dolo, pues como ha quedado dicho, pueden activar una u otra tutela a elección del acreedor.

\section{BiBLIOGRAFÍA}

Abeliuk Manasevic, René, Contrato de promesa, de opción y otros acuerdos previos ( $3^{a}$ edición, Santiago, Editorial AbeledoPerrot LegalPublishing, 2012).

Alcalde Silva, Jaime, La rescisión en el Código Civil chileno, en Departamento de Derecho Privado Universidad de Concepción (coordinador), Estudios de Derecho Civil V (Santiago, AbeledoPerrot LegalPublishing, 2010).

AlCalde Silva, Jaime, Bases para una sistematización de los efectos de la resolución por incumplimiento en Vidal OLIVAREs, Álvaro - Severin Fuster, Gonzalo - MejíAs Alonzo, Claudia (editores), Estudios de Derecho Civil X (Santiago, Editorial Thomson Reuters La Ley, 2015).

AlCalde Silva, Jaime, El contenido de la restitución derivada de la resolución por incumplimiento, en Libro Homenaje a Leslie Tomasello, en prensa.

Alonso Pérez, María Teresa, La función de las obligaciones precontractuales de advertencia en la formación del contrato de servicios (Estudio de Derecho Contractual Europeo), Indret Revista para el Análisis del Derecho 3 (2012), disponible en http:// www.indret.com/pdf/914_es.pdf.

BANFI DEL Río, Cristián, La asimilación de la culpa grave al dolo en la responsabilidad contractual en Chile, Revista Chilena de Derecho 27 (2000) 2. 
BARAONA GonZÁlez, Jorge, La nulidad de los actos jurídicos: consideraciones históricas y dogmáticas (Bogotá, Editorial Pontificia Universidad Javeriana-Ibáñez, 2012).

Barrientos Zamorano, Marcelo, Daños y deberes en las tratativas preliminares de un contrato (Santiago, Editorial LegalPublishing, 2008).

Barros Bourie, Enrique, Tratado de responsabilidad civil extracontractual (Santiago, Editorial Jurídica de Chile, 2006).

BARROS BOURIE, Enrique, La doctrina de la fuerza en el marco de la revisión contemporánea de la doctrina voluntarista del contrato, en Departamento de Derecho Privado Universidad de Concepción (editor), Barría Paredes, Manuel (coordinador), Estudios de Derecho Civil XI (Santiago, Thomson Reuters, 2016).

Barros Bourie, Enrique, Fuerza económica y abuso de posición de debilidad de la contraparte en el desarrollo jurisprudencial y doctrinario del derecho de contratos, en Corral Talciani, Hernán-Manterola Domínguez, Pablo (editores), Estudios de Derecho Civil XII (Santiago, Thomson Reuters, 2017).

Bohle Alar, Alejandra-Contardo GonzÁlez, Juan Ignacio, Criterios jurisprudenciales que determinan los requisitos de aplicación de la indemnización de perjuicios establecida en el artículo 1861 del Código Civil, en Contardo González, Juan Ignacio-De la Maza G., Iñigo, La Compraventa. Estudios (Santiago, Editorial Thomson Reuters, 2017).

Brantt Zumarán, María Graciela, El caso fortuito y su incidencia en el derecho de la responsabilidad contractual (Santiago, Editorial AbeledoPerrot LegalPublishing, 2010).

Carrasco Perera, Ángel, Derecho de contratos (2 edición actualizada y revisada, Navarra, Aranzadi Thomson Reuters, Cizur Menor, 2017).

Celedón Förster, Rosario-Silberman Veszpremi, Patricia, Responsabilidad precontractual por ruptura de negociaciones contractuales (Santiago, Editorial Jurídica de Chile, 2010).

CONTARDO GonZÁlez, Juan Ignacio, Indemnización y resolución por incumplimiento (Santiago, Editorial Thomson Reuters La Ley, 2015).

Chantepie, Gael-Latina, Mathias, La réforme du droit des obligations. Commentaire théorique et practique dans l' ordre du Code Civil (Paris, Dalloz, 2016).

Crespo Mora, María Carmen, Notas sobre la regulación del contrato de servicios en el derecho español y en el DCFR, en Bosh CAPDEVILle, Esteve (director), Nuevas Perspectivas del Derecho contractual (Barcelona, Editorial Bosh, 2012).

De la MaZa Gazmuri, Iñigo, El retiro unilateral como un caso de responsabilidad precontractual en De la MAZA GAZMuri, Iñigo (editor), Cuaderno de Análisis Jurídico III (Santiago, Ediciones Universidad Diego Portales, 2006).

De la MAZA, Iñigo, Los límites del deber precontractual de información (Madrid, Editorial Civitas-Thomson Reuters, 2010).

De la Maza Gazmuri, Iñigo, A propósito del artículo 1861, en Departamento de Derecho Privado Universidad de Concepción (coordinador), Estudios de Derecho Civil V (Santiago, Editorial AbeledoPerrot LegalPublishing, 2010).

De la Maza Gazmuri, Iñigo, La distribución del riesgo y la buena fe. A propósito del error, el dolo y los deberes precontractuales de información, Revista de Derecho de la Pontificia Universidad Católica de Valparaíso 37 (2011).

De la Maza Gazmuri, Iñigo, El contrato de promesa. La mirada de los tribunales (Santiago, Editorial Thomson Reuters, 2014).

De la MaZa GaZmuri, Iñigo, La tutela del comprador frente a la ausencia de calidades 
presupuestas en la cosa, en Revista de Derecho de la Pontificia Universidad Católica de Valparaiso 43 (2014), pp. 117-159.

De la Maza Gazmuri, Iñigo, Condiciones y obligaciones en el contrato de promesa. Corte Suprema, rol 512-2013, 24 de marzo de 2014. Cita en linea: CL/JUR/497/2014, Contratos Especiales, en Revista Chilena de Derecho Privado 22 (2014), pp. 271-284.

De la Maza Gazmuri, Iñigo, Afirmaciones conscientemente falsas y mediana diligencia. A propósito de la sentencia de la Corte Suprema de fecha 4 de abril de 2016, en Revista de Derecho Universidad Católica del Norte 23 (2016) 2.

De La Maza Gazmuri, Iñigo, Incumplimiento del vendedor. Estudios y sentencias (Santiago, Ediciones Der, 2017).

Del Olmo García, Pedro, La amenaza de incumplir un contrato como vicio del consentimiento (Valencia, Tirant lo Blanch, 2003).

Del Olmo García, Pedro, La cláusula "rebus", la renegociación de los contratos y la intimidación/vicio: tres lados de un triángulo, en Hornero Méndez, César- Espejo Lerdo de Tejada, Manuel-Oliva Blázquez, Francisco (directores), Murga Fernández, Juan Pablo (coordinador), Derecho de contratos: Nuevos escenarios y nuevas propuestas (Madrid, Thomson Reuters Aranzadi, 2016).

Deshayes, Olivier- Genicon, Thomas- Laithier, Yves Marie, Reforme du droit des contracts, du régimen générale et de la prevue des obligations. Comentaire article par article(Paris, LexisNexis, 2016).

Domínguez Águila, Ramón, Comentario de jurisprudencia: Responsabilidad precontractual. Principio de buena fe, aplicación del art. 1546 solo a la ejecución del contrato. Casación en el fondo por infracción de ley, en Revista de Derecho (Universidad de Concepción) 217-218 (2005).

Fabre-Magnan, Muriel, De l'obligation d'information dans les contrats. Essai d' une théorie (Paris, L.G.D.J., 1992).

Fabres, José Clemente, De la nulidad y la rescisión en Obras Completas, Vol. III (Santiago, Imprenta Cervantes, 1908).

Fenoy Picón, Nieves, La revisión del tratamiento de la imposibilidad inicial y del error en los contratos, a través del análisis jurídico de diversos textos jurídicos, en Anuario de Derecho Civil 70 (2017) 2.

García Rubio, María Paz- Otero Crespo, Marta, La responsabilidad precontractual en el derecho contractual europeo, en InDRET Revista para el análisis del Derecho 2 (2010), disponible en http://www.indret.com/pdf/731_es.pdf.

GuZMÁn BRITO, Alejandro, Sobre la relación entre las acciones de saneamiento de los vicios redhibitorios y las acciones comunes de indemnización, con especial referencia a su prescripción (opinión profesional), en Revista Chilena de Derecho Privado 9 (2007).

IHERING, Rudolf v., "Culpa in contrahendo oder Schadensersatz bei nichtigen oder nicht zur Perfektion gelangten Verträgen", Jherings Jahrbucher fur die Dogmatik des heutigen romischen und deutschen Privatrechts (1861) 4.

Lando, Ole- Beale, Hugh, Principios de derecho contractual europeo. Partes Iy II (traducción castellana de Pilar Barres Benlloch, José Embid Irujo, Fernando Martínez Sanz, Madrid: Colegios Notariales de España, 2003).

López Díaz, Patricia Verónica, La autonomía de la indemnización de daños por incumplimiento de un contrato bilateral en el Código Civil Chileno, (Santiago, Editorial Thomson Reuters LegalPublishing, 2015).

López Díaz, Patricia Verónica, La indemnización de daños por vicios redhibitorios como medio de tutela precontractual autónomo en el Código Civil Chileno: un tópico cuya 
procedencia y alcance aún permanecen difusos, en Departamento de Derecho Privado Universidad de Concepción (edit.), Manuel BARRÍA (coordinador), Estudios de Derecho Civil XI (Santiago, Editorial Thomson Reuters La Ley, 2016).

López Díaz, Patricia Verónica, Ponencia Los contratos preparatorios: entre la fase precontractual y contractual, presentada en la Cátedra por el Derecho Continental 2016 Los contratos en el nuevo derecho civil francés, el 9 de septiembre de 2016, inédita.

López Díaz, Patricia Verónica, Por la articulación de un sistema de medios de tutela precontractual en el Código Civil chileno, en Corral TalCiani, Hernán- Manterola GonzÁlez, Pablo, Estudios de Derecho Civil XII (Santiago, Thomson Reuters, 2017).

López DíAz, Patricia, Indemnización de daños autónoma por incumplimiento contractual. Vencimiento del término esencial. Infracción de obligaciones de advertencia. Daño moral y esfera de protección del contrato. Corte Suprema, 14 de noviembre de 2016, rol 5746-2016. Cita en Linea LEGALPUBLISHING CL/JUR/7557/2016, en Revista Chilena de Derecho Privado 28 (2017).

López DíAz, Patricia Verónica, La indemnización precontractual y contractual: divergencias y eventuales zonas de confluencia" en BARRÍA DÍAz, Rodrigo- FERRANTE, Alfredo- San Martín Neira, Lilian C., Presente y Futuro de la Responsabilidad Civil. Actas del Congreso Internacional de 3 y 4 de noviembre de 2016, Santiago de Chile (Santiago, Editorial Thomson Reuters, 2017).

López Díaz, Patricia Verónica, La tutela precontractual y contractual del acreedor en el Código Civil chileno: dos sistemas estructuralmente diversos, pero ¿plenamente coherentes y convergentes?, en Revista Chilena de Derecho Privado 29 (2017).

López Díaz, Patricia Verónica, Los supuestos y el alcance de la indemnización de daños como medio de tutela precontractual en el Código Civil chileno y su eventual confluencia con la indemnización por incumplimiento, en Revista Ius et Praxis, 24 (2018) 1, en prensa.

López DíAz, Patricia Verónica, La adaptación del contrato como medio de tutela precontractual en el Código Civil chileno, en Revista de Derecho de Valdivia 31 (2018) 1 , en prensa.

López Díaz, Patricia Verónica, La ruptura de las tratativas preliminares como una justificada excepción al principio de libertad contractual y un particular supuesto de indemnización precontractual, Estudios de Derecho de Contratos en Homenaje a Antonio Manuel Morales Moreno, en prensa.

LÓpez DíAz, Patricia Verónica, Tutela precontractual versus tutela contractual en el Código Civil chileno: ¿efecto espejo o reflejo?, en Estudios de Derecho Civil XIII, 2018, en prensa.

Mejías Alonzo, Claudia, El incumplimiento resolutorio en el Código Civil (Santiago, Editorial AbeledoPerrot LegalPublishing, 2011).

Mejías Alonzo, Claudia Carolina, Una revisión crítica de los efectos de la resolución por incumplimiento y una propuesta de solución, en Revista Ius et Praxis año 22 (2016) 1.

Morales Moreno, Antonio Manuel, El error en los contratos (Madrid, Editorial Ceura, 1988).

Morales Moreno, Antonio Manuel, Incumplimiento de contrato y lucro cesante (Navarra, Editorial Thomson Civitas, 2010).

Morales Moreno, Antonio Manuel, ¿Es posible construir un sistema precontractual de remedios? Reflexiones sobre la Propuesta de Modernización del Derecho de Obligaciones y Contratos en el marco del Derecho europeo, en Albiez Dohrmann, 
Klaus Jochen (director), Palazón Garrido, María Luisa - Méndez Serrano, María del Mar (coordinadores), Derecho Privado Europeo y Modernización del Derecho Contractual en España (Barcelona, Editorial Atelier, 2011).

Morales Moreno, Antonio Manuel, Los Principios latinoamericanos de derecho de los contratos. Un debate abierto sobre grandes cuestiones jurídicas de la contratación, Anuario de Derecho Civil 67 (2014) 1.

Oviedo Albán, Jorge, Indemnización de perjuicios por vicios redhibitorios en el Código Civil chileno-colombiano, en Revista Pontificia Universidad Javeriana 129 (2014).

Orduña Moreno, Francisco Javier-Martínez Velencoso, Luz María, La moderna configuración de la cláusula rebus sic stantibus. Desarrollo de la nueva doctrina jurisprudencial aplicable y derecho comparado ( $2^{a}$ edición, Navarra, Civitas Thomson Reuters, 2017).

PANTALEÓN, Fernando, Responsabilidad precontractual: propuestas de regulación para un futuro Código Latinoamericano de Contratos, en Anuario de Derecho Civil 64 (2011) 3.

Peñailillo Arévalo, Daniel, Obligaciones. Teoría general y clasificaciones. La resolución por incumplimiento(Santiago, Editorial Jurídica de Chile, 2003).

Peñailillo Arévalo, Daniel, El cumplimiento ficto de la condición, en Revista de Derecho de la Universidad de Concepción 178 (1985).

Pizarro Wilson, Carlos, Hacia un sistema de remedios al incumplimiento contractual, en GuZmán Brito, Alejandro (editor), Estudios de Derecho Civil III (Santiago, Editorial Lexis Nexis, 2008).

Pizarro Wilson, Carlos, Contra el efecto retroactivo de la resolución por incumplimiento contractual, en Elorriaga De Bonis, Fabián (coordinador), Estudios de Derecho Civil VII (Santiago, Editorial AbeledoPerrot LegalPublishing Thomson Reuters, 2012).

PiZArRo Wilson, Carlos, Notas acerca de los limites a la pretensión de cumplimiento del contrato, en Revista de Derecho Universidad Católica del Norte 21 (2014) 1.

Puelma ACCORSI, Álvaro, Contratación comercial moderna: actos y contratos preparatorios, promesa, opción, cierre de negocio, comisión, corretaje, representación comercial, agencia, concesión mercantil, frachising, distribución, suministro, licencias, know how, apertura de créditos (Santiago, Editorial Jurídica de Chile, 2002).

Prado López, Pamela, La colaboración del acreedor en los contratos civiles (Santiago, Editorial Thomson Reuters La Ley, 2015).

Prado López, Pamela, El dolo causal: su repercusión en el contrato, en Revista Ius et Praxis 22 (2016) 2.

RosEnde ÁlVAREZ, Hugo, Algunas consideraciones sobre la responsabilidad precontractual (Valparaíso, Ediciones Universitarias de Valparaíso, 1979).

Rodríguez Grez, Pablo, Inexistencia y nulidad en el Código Civil. Teoría Bimembre de la Nulidad (Santiago, Editorial Jurídica de Chile, 1995). -Rodríguez Grez, Pablo, Nuevas tendencias de la responsabilidad (Santiago, Editorial AbeledoPerrot LegalPublishing, 2011).

Rossel SaAvedra, Enrique, Teoría de las nulidades (Santiago, Balcells, 1926).

San Martín Neira, Lilian, Responsabilidad precontractual por ruptura injustificada de negociaciones. Corte Suprema, Rol 1872/2010, en Revista Chilena de Derecho 40 (2013) 1.

SAn Martín Neira, Lilian, La teoría de la inexistencia y su falta de cabida en el Código Civil Chileno, en Revista Chilena de Derecho 42 (2015) 3. 
SolÉ Feliú, Josep, La intimidación o amenaza como vicio del consentimiento contractual: textos, principios europeos y propuestas de reforma en España, en Indret, Revista para el Análisis del derecho (2016) 4, disponible en http://www.indret. com/pdf/1261_es.pdf.

Ugarte Godoy, José Joaquín, La inexistencia jurídica, en Departamento de Derecho Privado Universidad de Concepción (editor), BarRía PAREdes, Manuel (coordinador), Estudios de Derecho Civil XI (Santiago, Editorial Thomson Reuters, 2016).

UNidRoit, Instituto Internacional para la Unificación del Derecho Privado, en Garro, A.M. (director), Rodríguez Olmos, Javier Mauricio-Perales VISCASILLAS, Pilar (colabores), Principios UNIDROIT sobre los contratos comerciales internacionales (Madrid, Ediciones UNIDROIT, 2010).

Vial DEL Río, Víctor, Teoría general del acto jurídico (5ª edición, Santiago, Editorial jurídica de Chile, 2003).

Vidal Olivares, Álvaro, La pretensión de cumplimiento específico y su inserción en el sistema de remedios por incumplimiento en el Código Civil, en Corral TalCiani, Hernán-Rodríguez Pinto, María Sara (editores), Estudios de Derecho Civil II (Santiago, Editorial Lexis Nexis, 2006).

Vidal Olivares, Álvaro, Cumplimiento e Incumplimiento contractual en el Código Civil. Una perspectiva más realista, en Revista Chilena de Derecho 34 (2007) 1.

VIDAl Olivares, Álvaro, La carga de mitigar las pérdidas del acreedor y su incidencia en el sistema de remedios por incumplimiento, en GUZMÁn BRITO, Alejandro (editor), Estudios de Derecho Civil III (Santiago, Editorial Lexis Nexis, 2008).

Zuloaga Ríos, Isabel Margarita, Teoría de la responsabilidad precontractual. Aplicaciones en la formación del consentimiento de los contratos (Santiago, Editorial Lexis Nexis, 2006).

\section{JURISPRUDENCIA CITADA}

Consorcio Transportes Trancura Ltda. con Tocale Tuna, Romilio: Corte Suprema, 19 de enero de 2010 (casación en el fondo), en www.microjuris.com, $\mathrm{N}^{\circ} \mathrm{MJCH}_{-}$ MJJ22895.

Inmobiliaria Los Canelos S.A. con Inmobiliaria e Inversiones Sevilla Ltda.: Corte Suprema, 24 de marzo de 2014 (casación en el fondo), en www.vlex.com, $\mathrm{N}^{\circ}$ VLEX 500403234 .

Glide Inversiones Ltda. con Compañia de Inversiones y Desarrollo Sur S.A.: Corte Suprema, 19 de mayo de 2008 (casación en el fondo), en www.vlex.com, $\mathrm{N}^{\circ}$ VLEX 41113399.

Lange Haensgen con Ibáñez Santa María: Corte Suprema, 23 de septiembre de 2015 (casación en la forma y casación en el fondo), en www.vlex.com, $\mathrm{N}^{\circ}$ VLEX 583125862.

Sociedad Agricola Santa Anita con Faenadora El Milagro S.A.: Corte Suprema, 9 de diciembre de 2015 (casación en el fondo), en www.vlex.com, N VLEX-589170582.

Urrea Puentes con Corpbanca: Corte Suprema, 12 de abril de 2012 (casación en el fondo), en www.vlex.com, $\mathrm{N}^{\circ}$ VLEX 436253870. 
